\title{
In situ detection of atomic and molecular iodine using Resonance and Off-Resonance Fluorescence by Lamp Excitation: ROFLEX
}

\author{
J. C. Gómez Martín ${ }^{1}$, J. Blahins ${ }^{2}$, U. Gross ${ }^{2}$, T. Ingham ${ }^{3,4}$, A. Goddard ${ }^{3}$, A. S. Mahajan ${ }^{1}$, A. Ubelis ${ }^{2}$, and \\ A. Saiz-Lopez ${ }^{1}$ \\ ${ }^{1}$ Laboratory for Atmospheric and Climate Science (CIAC), CSIC, Toledo, Spain \\ ${ }^{2}$ Institute for Atomic Physics and Spectroscopy (IAPS), University of Latvia, Latvia \\ ${ }^{3}$ School of Chemistry, University of Leeds, Leeds, UK \\ ${ }^{4}$ National Centre for Atmospheric Science, School of Chemistry, University of Leeds, UK
}

Received: 11 August 2010 - Published in Atmos. Meas. Tech. Discuss.: 25 August 2010

Revised: 8 December 2010 - Accepted: 3 January 2011 - Published: 19 January 2011

\begin{abstract}
We demonstrate a new instrument for in situ detection of atmospheric iodine atoms and molecules based on atomic and molecular resonance and off-resonance ultraviolet fluorescence excited by lamp emission. The instrument combines the robustness, light weight, low power consumption and efficient excitation of radio-frequency discharge light sources with the high sensitivity of the photon counting technique. Calibration of $\mathrm{I}_{2}$ fluorescence is achieved via quantitative detection of the molecule by Incoherent Broad Band Cavity-enhanced Absorption Spectroscopy. Atomic iodine fluorescence signal is calibrated by controlled broad band photolysis of known $\mathrm{I}_{2}$ concentrations in the visible spectral range at atmospheric pressure. The instrument has been optimised in laboratory experiments to reach detection limits of $1.2 \mathrm{pptv}$ for I atoms and $13 \mathrm{pptv}$ for $\mathrm{I}_{2}$, for $S / N=1$ and $10 \mathrm{~min}$ of integration time. The ROFLEX system has been deployed in a field campaign in northern Spain, representing the first concurrent observation of ambient mixing ratios of iodine atoms and molecules in the $1-350 \mathrm{pptv}$ range.
\end{abstract}

\section{Introduction}

Studies of atmospheric iodine chemistry have been mainly motivated by its impact on the oxidizing capacity of the marine boundary layer (MBL) by catalyzing $\mathrm{O}_{3}$ destruction (Davis et al., 1996; Allan et al., 2000; Saiz-Lopez et al., 2007; Read et al., 2008). Another focus of interest is the involvement of iodine oxides in the formation of ultra-fine

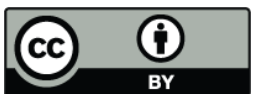

Correspondence to: A. Saiz-Lopez (a.saiz-lopez@ciac.jccm-csic.es) particles in the coastal MBL, which may grow to a size where they can act as cloud condensation nuclei (O'Dowd and Hoffmann, 2005).

Iodine is released to the atmosphere mainly in the form of $I_{2}$ (McFiggans et al., 2004; Saiz-Lopez and Plane, 2004) and alkyl iodides such as $\mathrm{CH}_{3} \mathrm{I}$ and $\mathrm{CH}_{2} \mathrm{I}_{2}$ (Carpenter et al., 2003) by coastal and oceanic biological sources (e.g. phytoplankton and macroalgae). In the troposphere, I atoms are released by photolysis of $\mathrm{I}_{2}$ and iodocarbons.

The measurement of atmospheric $\mathrm{I}_{2}$ was first reported by Saiz-Lopez and Plane (2004) at Mace Head (Ireland), who detected up to $95 \mathrm{pptv}$ at night and $25 \mathrm{pptv}$ during the day using Long Path-Differential Optical Absorption Spectroscopy (LP-DOAS). Subsequent LP-DOAS I 2 measurements at Mace Head and Roscoff (France) have also been reported (Peters et al., 2005; Mahajan et al., 2009; Huang et al., 2010). Quantitative detection by LP-DOAS provides mixing ratios that are spatially averaged over several $\mathrm{km}$, and are therefore well suited for measuring background (e.g. remote oceanic) mixing ratios. However, in the mid-latitude coastal MBL, where the spatial distribution of iodine emissions is likely to be heterogeneous, in situ measurements near the iodine emission sources are very valuable. In situ techniques such as online detection by Broadband Cavity Ring Down Spectroscopy (BBCRDS) (Bitter et al., 2005; Leigh et al., 2010), and Atmospheric Pressure Chemical Ionization with Tandem Mass Spectrometry (APCI/MS/MS) (Finley and Saltzman, 2008), and analysis of diffusion denuder air samples with Inductively Coupled Plasma Mass Spectrometry (ICP-MS) (Saiz-Lopez et al., 2006) or Gas Chromatography Mass Spectrometry (GC-MS) (Huang et al., 2010), have also been applied to the quantitative detection of atmospheric $\mathrm{I}_{2}$. 
Table 1. Comparison of characteristics and performance of a selection of RF instruments reported in the literature.

\begin{tabular}{lllllllll}
\hline Atom $^{\mathrm{a}}$ & Reference & $\lambda \mathrm{b}$ & $P_{\text {cell }}{ }^{\mathrm{c}}$ & $C / 10^{-7^{\mathrm{d}}}$ & $C_{N} / 10^{-7^{\mathrm{e}}}$ & $S_{\mathrm{b}}{ }^{\mathrm{f}}$ & $t^{\mathrm{g}}$ & LOD $^{\mathrm{h}}$ \\
\hline $\mathrm{Cl}$ & Brune et al. (1985) & 118.9 & 40 & 100 & - & 50 & 1 & sub-pptv \\
$\mathrm{Br}$ & Avallone et al. (1995) & $115.9-131.7$ & 40 & 15 & - & 4500 & 30 & 1 \\
$\mathrm{I}$ & Bale et al. (2008) & $178.3,183.0$ & 20 & 0.2 & 7.6 & 200 & 2 & 5 \\
& This work & $178.3,183.0$ & 70 & 0.5 & 5.4 & 365 & 10 & 1.2 \\
\hline
\end{tabular}

${ }^{\mathrm{a}}$ Instruments designed for detection of $\mathrm{XO}(\mathrm{X}=\mathrm{Cl}, \mathrm{Br})$ by chemical conversion to $\mathrm{X} .{ }^{\mathrm{b}}$ Wavelength of resonance lines in $\mathrm{nm} .{ }^{\mathrm{c}}$ Pressure inside the fluorescence cell in Torr.

${ }^{\mathrm{d}}$ Sensitivity constant in $\mathrm{c} \mathrm{s}^{-1}$ atom ${ }^{-1} \mathrm{~cm}^{3}$. ${ }^{\mathrm{e}}$ Fluorescence cell sensitivity constant of boundary layer instruments. ${ }^{\mathrm{f}}$ Background signal in $\mathrm{c} \mathrm{s}^{-1} .{ }^{\mathrm{g}}$ Integration time in minutes.

${ }^{\mathrm{h}}$ Mixing ratio detection limit in pptv for $S / N=1$.

Resonance fluorescence (RF) instruments have been extensively used in atmospheric research for in situ detection of trace species like gaseous elemental mercury and halogen oxides. In RF instruments, the halogen oxide species is detected via titration with an excess of NO, and subsequent release and detection of the halogen atom using a microwave or radio-frequency lamp as excitation source. In particular, chlorine and bromine RF instruments were developed during the late 70's and the 80's of the last century for the detection of $\mathrm{ClO}$ and $\mathrm{BrO}$ in the context of the study of stratospheric halogen-catalysed ozone depletion (Anderson et al., 1977, 1980; Brune et al., 1985, 1989; Brune and Anderson, 1986; Avallone et al., 1995). A bromine oxide boundary layer instrument has also been reported (Avallone et al., 2003). Bale et al. (2008) pioneered the detection of atmospheric atomic iodine by constructing, characterising and deploying in the field an instrument for the detection of atomic iodine using the RF technique. As a proxy for $\mathrm{I}_{2}$, Bale et al. (2008) used the total photolabile iodine content of the sampled air, derived from the iodine atom signal observed after visible broad band photolysis of ambient iodine bearing molecules, which in a coastal environment with macroalgae emissions would correspond to a large extent to $\mathrm{I}_{2}$ (McFiggans et al., 2004). A comparison of characteristics and performance of halogen RF instruments is shown in Table 1.

Here we present a new RF instrument for in situ detection of atomic and molecular iodine. The most important development with respect to Bale et al. (2008) is the inclusion of a second detector for collection of molecular iodine off-resonance fluorescence (ORF). This enables: (i) using a much simpler method for calibration of the fluorescence signal by $I_{2}$ absorption and photolysis, and (ii) measuring concurrently and directly a major iodine source $\left(\mathrm{I}_{2}\right)$ and active iodine atoms (I). Another important development is the use of a radio-frequency discharge iodine lamp. This type of discharge has been regularly used in chlorine and bromine field instruments (e.g. Brune et al., 1989). Radio-frequency discharge coils have several advantages over microwave cavities (Brewer and Tellinghuisen, 1971; Loewenstein and Anderson, 1985; Aleksandrov et al., 1985): lower cost, lighter and smaller generator, lower power consumption and narrower atomic line width.
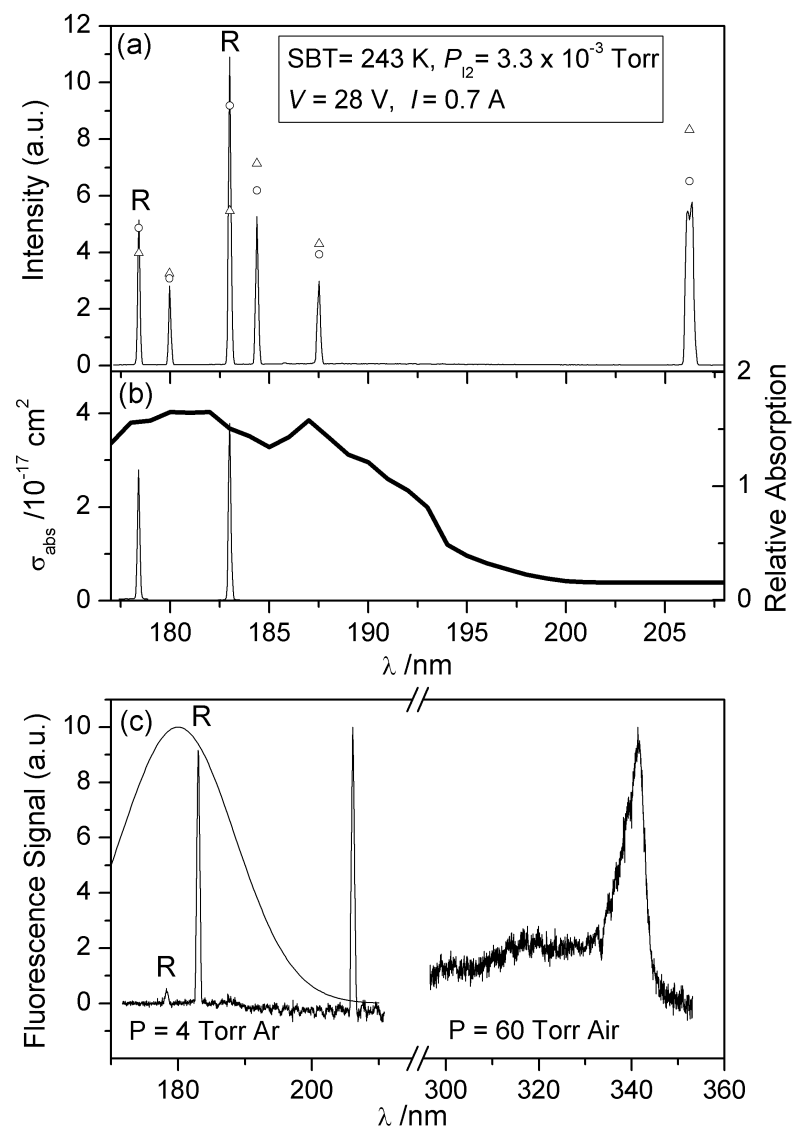

Fig. 1. ROFLEX excitation (a), absorption (b) and fluorescence (c) stages. (a) shows a lamp emission spectrum for a side branch temperature (SBT) of $243 \mathrm{~K}$, recorded with a VUV grating spectrometer and a CCD $(R=$ resonance line $)$. Line peaks at SBT $=293 \mathrm{~K}$ $(\triangle)$ and $273 \mathrm{~K}(\bigcirc)$ are also shown. (b) shows the $\mathrm{I}_{2} \mathrm{UV}$ absorption cross sections (thick line) reported by Roxlo and Mandl (1980) and a relative absorption spectrum of atomic iodine in air (Spietz et al., 2001). (c) shows atomic (resonance) and molecular (offresonance) dispersed fluorescence (see text for details). The transmittance curve of the VUV filter is shown as a solid thin line. The absence of the $206.163 \mathrm{~nm}$ line in the atomic absorption spectrum (b) is due to efficient quenching of $\mathrm{I}\left({ }^{2} P_{1 / 2}\right)$ by oxygen (Young and Houston, 1983). 
Table 2. Wavelength, excited state and oscillator strength of halogen atom resonance lines used in RF instruments reported in the literature.

\begin{tabular}{|c|c|c|c|}
\hline Ground state & $\lambda / \mathrm{nm}$ & Excited state & Oscillator strength \\
\hline \multirow[t]{3}{*}{$\mathrm{Cl}\left(3 s^{2} 3 p^{5}\left({ }^{2} P_{3 / 2}^{\circ}\right)\right)$} & 118.877 & $3 s^{2} 3 p^{4}\left({ }^{1} D\right) 4 s\left({ }^{2} D_{5 / 2}\right)$ & $(6.8 \pm 0.7) \times 10^{-2^{\mathrm{a}}}$ \\
\hline & 133.573 & $3 s^{2} 3 p^{4}\left({ }^{3} P\right) 4 s\left({ }^{2} P_{1 / 2}\right)$ & $2.33 \times 10^{-2^{b}}$ \\
\hline & 134.724 & $3 s^{2} 3 p^{4}\left({ }^{3} P\right) 4 s\left({ }^{2} P_{3 / 2}\right)$ & $1.14 \times 10^{-1^{b}}$ \\
\hline \multirow{11}{*}{$\operatorname{Br}\left(4 p^{5}\left({ }^{2} P_{3 / 2}^{\circ}\right)\right)$} & 115.903 & $4 p^{4}\left({ }^{3} P\right) 6 s\left({ }^{2} P_{1 / 2}\right)$ & $\mathrm{c}$ \\
\hline & 118.616 & $4 p^{4}\left({ }^{3} P\right) 4 d\left({ }^{4} P_{5 / 2}\right)$ & $\mathrm{c}$ \\
\hline & 118.938 & $4 p^{4}\left({ }^{3} P\right) 4 d\left({ }^{4} P_{3 / 2}\right)$ & $\mathrm{c}$ \\
\hline & 121.600 & $4 p^{4}\left({ }^{3} P\right) 6 s\left({ }^{4} P_{5 / 2}\right)$ & $\mathrm{c}$ \\
\hline & 122.441 & $4 p^{4}\left({ }^{3} P\right) 4 d\left({ }^{4} P_{3 / 2}\right)$ & $\mathrm{c}$ \\
\hline & 122.805 & $4 p^{4}\left({ }^{3} P\right) 4 d\left({ }^{4} P_{1 / 2}\right)$ & c \\
\hline & 126.166 & $4 p^{4}\left({ }^{3} P\right) 4 d\left({ }^{4} D_{5 / 2}\right)$ & c \\
\hline & 131.737 & $4 p^{4}\left({ }^{2} D_{2}\right) 5 s\left({ }^{2} D_{3 / 2}\right)$ & $\mathrm{c}$ \\
\hline & 148.845 & $4 p^{4}\left({ }^{3} P\right) 5 s\left({ }^{2} P_{3 / 2}\right)$ & $(4.1 \pm 0.4) \times 10^{-2^{\mathrm{d}}}$ \\
\hline & 154.065 & $4 p^{4}\left({ }^{3} P\right) 5 s\left({ }^{4} P_{3 / 2}\right)$ & $(4.9 \pm 0.6) \times 10^{-2^{\mathrm{d}}}$ \\
\hline & 157.639 & $4 p^{4}\left({ }^{3} P\right) 5 s\left({ }^{4} P_{5 / 2}\right)$ & $(1.16 \pm 0.08) \times 10^{-3^{\mathrm{d}}}$ \\
\hline \multirow[t]{5}{*}{$\mathrm{I}\left(5 p^{5}\left({ }^{2} P_{3 / 2}^{\circ}\right)\right)$} & 142.137 & $5 p^{4}\left({ }^{3} P_{2}\right) 5 d\left({ }^{2}[2]_{3 / 2}\right)$ & $(2.9 \pm 0.7) \times 10^{-2^{\mathrm{e}}}$ \\
\hline & 142.550 & $5 p^{4}\left({ }^{3} P_{2}\right) 5 d\left({ }^{2}[2]_{5 / 2}\right)$ & $(5.3 \pm 1.4) \times 10^{-2^{\mathrm{e}}}$ \\
\hline & 145.740 & $5 p^{4}\left({ }^{3} P_{2}\right) 5 d\left({ }^{2}[0]_{1 / 2}\right)$ & $(8.8 \pm 2.6) \times 10^{-3^{\mathrm{e}}}$ \\
\hline & 178.276 & $5 p^{4}\left({ }^{3} P_{2}\right) 6 s\left({ }^{2}[2]_{3 / 2}\right)$ & $1.29 \times 10^{-1^{\mathrm{f}}}(4.52 \pm 0.42) \times 10^{-2^{\mathrm{d}}}$ \\
\hline & 183.038 & $5 p^{4}\left({ }^{3} P_{2}\right) 6 s\left({ }^{2}[2] 5 / 2\right)$ & $\begin{aligned} 1.2 \times 10^{-2 f} & (1.67 \pm 0.23) \times 10^{-3^{\mathrm{d}}} \\
& (3.87 \pm 0.57) \times 10^{-3^{\mathrm{g}}}\end{aligned}$ \\
\hline
\end{tabular}

a (Schwab and Anderson, 1982). ${ }^{b}$ (Radziemski and Kaufman, 1969). ${ }^{c}$ Oscillator strengths are not available. Excited states from (Tech, 1963). ${ }^{d}$ (Clyne and Townsend, 1974).

e (Baklanov and et al., 1997). ${ }^{\mathrm{f}}$ (Lawrence, 1967). ${ }^{\mathrm{g}}$ (Spietz et al., 2001).

The instrument has been characterised in the laboratory and deployed in a short campaign in the northern Spanish coast to test its performance in the field.

\section{Principle of Resonance and Off-Resonance Fluorescence by Lamp Excitation (ROFLEX)}

The spectrum of atomic iodine shows a number of strong lines between $170 \mathrm{~nm}$ and $210 \mathrm{~nm}$ (Fig. 1a). The two most prominent resonance transitions are $5 p^{5}\left({ }^{2} P_{3 / 2}^{\circ}\right) \leftarrow$ $5 p^{4}\left({ }^{3} P_{2}\right) 6 s\left({ }^{2}[2]_{3 / 2}\right)$ at $178.276 \mathrm{~nm}$ and $5 p^{5}\left({ }^{2} P_{3 / 2}^{\circ}\right) \leftarrow$ $5 p^{4}\left({ }^{3} P_{2}\right) 6 s\left({ }^{2}[2]_{5 / 2}\right)$ at $183.038 \mathrm{~nm}$ (Lawrence, 1967; Clyne and Townsend, 1974; Brewer et al., 1983). Another important line at $206.163 \mathrm{~nm}$ corresponds to the non-resonance transition $5 p^{5}\left({ }^{2} P_{1 / 2}^{\circ}\right) \leftarrow 5 p^{4}\left({ }^{3} P_{2}\right) 6 s\left({ }^{2}[2]_{3 / 2}\right)$. Oscillator strength measurements (see Table 2) indicate that the $178.276 \mathrm{~nm}$ transition is $\sim 20$ times stronger than the $183.083 \mathrm{~nm}$ line (Clyne and Townsend, 1974; Spietz et al., 2001). However, such factor is not observed in emission spectra from iodine lamps (Hikida et al., 1983; Loewenstein and Anderson, 1985; Aleksandrov et al., 1985) as a result of the relative population of the two states of the ${ }^{2}[2]_{J}$ multiplet. Assuming equilibrium at the kinetic temperature of the gas ( $T \sim 900 \mathrm{~K}$, Spietz et al., 2001), the relative population of the $J=3 / 2$ and $J=5 / 2$ states would be $1: 15$, which partially balances the ratio of oscillator strengths. Unavoidable self-absorption inside the light source also contributes to the relative intensities of lines, making them differ from the expected theoretical values (Braun and Carrington, 1969).

In RF applications, fluorescence photons are collected perpendicularly to the light source axis in order to preclude detection of excitation radiation. The count rate from atomic iodine RF registered by a suitable detector is given by (Anderson et al., 1980; Holland et al., 1995):

$$
\begin{aligned}
S(\mathrm{I}) & =\left[\int_{\text {line }} F(\lambda) \sigma_{\mathrm{I}}(\lambda) d \lambda\right] Y\left(P_{\text {cell }}\right) \Phi \tau \gamma \frac{P_{\text {cell }}}{P_{\text {env }}}[\mathrm{I}] \\
& =C_{\mathrm{I}}(F)[\mathrm{I}]
\end{aligned}
$$

where the bracketed part is the absorption factor (convolution of the absorption cross section $\sigma(\lambda)$ and the lamp photon flux $F(\lambda)$ over a resonance line, see e.g. Ingle and Crouch, 1988), $Y\left(P_{\text {cell }}\right)$ is the fluorescence yield from the $5 p^{4}\left({ }^{3} P_{2}\right) 6 s\left({ }^{2}[2]_{J}\right)$ state, $\Phi$ is a detection efficiency factor, encompassing geometrical and optical factors and detector quantum efficiency (assuming an uniform spectral sensitivity), $\tau$ is the attenuation due to absorption of excitation and fluorescence radiation by other species present in the sample, $\gamma$ is the sampling efficiency (fraction of iodine that is 


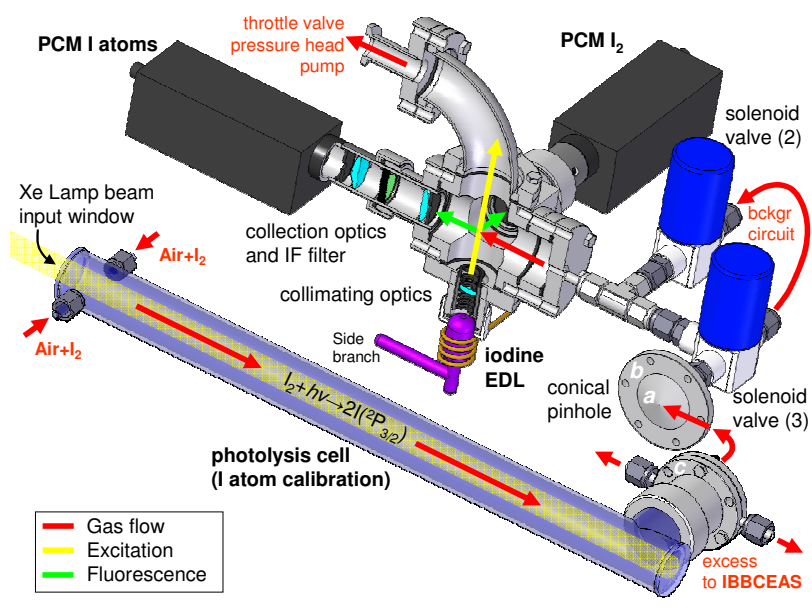

Fig. 2. Sketch of the ROFLEX instrument and calibration flow tube. A cutaway section of the fluorescence cell is displayed showing the excitation and fluorescence collection geometry. The sample intake is made through the pinhole (a). In field measurements, the pinhole is exposed to the environment. In calibration model, the flange (c) is mounted on top of (b). The solenoid valves allow switching between direct sampling from the environment and iodine-free air sampling from the background circuit (bckgr).

not lost in the inlet walls and reaches the fluorescence cell), $P_{\text {env }}$ and $P_{\text {cell }}$ are the pressure in the environment and in the fluorescence cell respectively, and [I] is the I atom concentration in the environment. For a given lamp flux, the product of the absorption and efficiency factors is the so-called sensitivity constant $C_{\mathrm{I}}(F)$, which is normally determined using a photochemical calibration technique (Anderson et al., 1980; Bale et al., 2008).

Molecular iodine presents a strong, highly structured absorption feature in the same spectral region $(170 \mathrm{~nm}-$ $210 \mathrm{~nm}$ ), known as the Cordes bands ( $D \leftarrow X$ system), with absorption cross sections of $\sim 2 \times 10^{-17} \mathrm{~cm}^{2}$ molecule $^{-1}$ at $188 \mathrm{~nm}$ (0.14 nm FWHM) (Myer and Samson, 1970; Roxlo and Mandl, 1980; Saiz-Lopez et al., 2004), Fig. 1b. After absorption of vacuum ultraviolet (VUV) photons, fluorescence from the $D$ ion-pair state back to the ground state exhibits an ordinary bound to bound spectrum together with a bound to free diffuse quantum interference spectrum around $325 \mathrm{~nm}$ known as the McLennan bands (Tellinghuisen, 1974; Exton and Balla, 2004). Concurrently, a significant fraction of the initial $D$ state population is collisionally transferred to the $D^{\prime}$ state at increasing buffer gas pressure, resulting in strong fluorescence in the $D^{\prime} \rightarrow A^{\prime}$ band at $340 \mathrm{~nm}$ (Fig. 1c). Similarly to Eq. (1), the count rate from molecular iodine ORF excited from the lamp emission is given by:

$$
\begin{aligned}
S\left(\mathrm{I}_{2}\right) & =\left[\int_{\lambda_{1}}^{\lambda_{2}} F(\lambda) \sigma_{\mathrm{I}_{2}}(\lambda) Y\left(\lambda, P_{\text {cell }}\right) d \lambda\right] \Phi \tau \gamma \frac{P_{\text {cell }}}{P_{\text {env }}}\left[\mathrm{I}_{2}\right] \\
= & C_{\mathrm{I}_{2}}(F)\left[\mathrm{I}_{2}\right]
\end{aligned}
$$

where the convolution takes place over the spectral range of lamp emission overlapping with the $\mathrm{I}_{2}$ absorption cross section. The involvement of several excited states and concurrent collisional de-excitation are taken into account by including the fluorescence yield $Y\left(\lambda, P_{\text {cell }}\right)$ in the integral (see Eq. 9) in Exton and Balla (2004).

Our approach for simultaneous detection of $\mathrm{I}$ and $\mathrm{I}_{2}$ utilises the fact that both atomic and molecular iodine can be excited with the same iodine line source, so that the resulting fluorescence arising from the same excitation volume can be selectively collected at right angles using two different detectors with enhanced sensitivity for the spectral range of interest in each case. Figure 2 shows schematically how this concept has been materialised. An important requirement for the instrument is achieving similar sensitivities for both species. In principle, the challenge is to bridge $\sim 3$ orders of magnitude difference in the absorption cross sections of iodine atoms $\left(\sigma(183 \mathrm{~nm}) \sim 5 \times 10^{-14} \mathrm{~cm}^{2}\right.$ atom $\left.{ }^{-1}\right)$ and molecules $\left(\sigma(188 \mathrm{~nm}) \sim 2 \times 10^{-17} \mathrm{~cm}^{2}\right.$ molecule $\left.{ }^{-1}\right)$, which suggest a much smaller sensitivity to $I_{2}$. Multiple wavelength excitation of $I_{2}$ helps to partially compensate that difference, since both resonance and non-resonance atomic iodine lines available from the line source overlap with the Cordes bands as shown in Fig. 1a and b. On the other hand, the sensitivity to I atoms is reduced by the strong Schumman-Runge bands of $\mathrm{O}_{2}$ (Yoshino et al., 1992) and a band pass interference filter required to minimise interference from $\mathrm{I}_{2}$ (Fig. 1c).

\section{Instrument set-up}

\subsection{Fluorescence cell and background circuit}

Figure 2 shows a cutaway section of the fluorescence cell. The cell itself is a standard CF-flanged 6-way crossing (Kurt J. Lesker), which consist of a bored stainless steel cube (70 $\mathrm{mm}$ side) with $38 \mathrm{~mm}$ diameter holes bored through each face. CF to quick-connect fittings are employed to couple in three perpendicular axes two photon counting modules (PCM) and the radiation source, each with their corresponding collecting and collimating optical assemblies (see below). Opposite to the lamp, a standard CF-flanged $90^{\circ}$ round elbow prevents scattered light from the walls to leak into the PCMs axes. The CF elbow leads to the exhaust of the fluorescence cell, connected to a 100 Torr $(\sim 133 \mathrm{hPa})$ Pressure head (MKS Baratron) and isolated by a butterfly valve from a rotary vane vacuum pump (Pfeiffer DUO 5). All inner parts of the fluorescence cell are coated with a 50:50 mixture of antireflective coating (Alion MH2200) and carbon black (AlfaAesar) to minimise light scattering from the walls (Hottle et al., 2009). Ambient air is drawn through the fluorescence cell at a rate of 3-6 slm through a $0.8 \mathrm{~mm}$ diameter stainless steel conical pinhole. A number of combinations of pinholes and pumps, resulting in different ranges of accessible pressures, 
have been tried in order to optimise the fluorescence signal. These optimisation experiments are discussed in Sect. 4.

Automatic switching between environment air sampling and an "iodine-cleaning" secondary circuit (see below) is performed by using two synchronised solenoid valves (Parker). Such secondary circuit consists of a $100 \mathrm{~cm}$ opaque tube where I atoms are scavenged by ambient ozone and wall deposition in the absence of light, and a cold trap where both $\mathrm{I}$ and $\mathrm{I}_{2}$ are frozen away from the flow. The cold trap is an aluminium box containing an inner array of blades for surface enhancement, sandwiched between two thermoelectric modules (Ferrotec), whose warm side is water-cooled via copper blocks. Temperatures inside the box can reach down to $253 \mathrm{~K}$. Experiments have been carried out to check the trapping efficiency, where it has been found that the cold trap works well both for I and $\mathrm{I}_{2}$ below $263^{\circ} \mathrm{C}$ in an $80 \%$ relative humidity environment. To do such study and for calibration purposes, zero synthetic air can also be supplied through the 2 way solenoid shown in Fig. 2 to facilitate the measurement of the background signal during the calibration stage.

\subsection{Fluorescence detection}

The collection optic axes are separated from the cell by the last optic element of each assembly. These are contained inside $10 \mathrm{~cm}$ long cylindrical lens holders (Thorlabs) and consist of two $50 \mathrm{~mm}$ focal length $\mathrm{CaF}_{2}$ plano-convex lenses and a band pass filter. An interference filter centred at $185 \mathrm{~nm}$ with $20 \mathrm{~nm}$ FWHM with $20 \%$ peak transmission at the central wavelength (Semrock 180-N-1D) is employed to isolate the resonance lines of iodine from $\mathrm{I}_{2}$ emission (Fig. 1c). A UV filter (Thorlabs FGUV5, 240-395 nm) is used to select the $325 \mathrm{~nm}$ and $340 \mathrm{~nm}$ fluorescence band systems of $I_{2}$. The I atom RF axis is vacuum sealed and continuously evacuated using a small rotary vane pump (Pffeifer DUO 2.5). In order to enhance the $I_{2}$ fluorescence signal, a concave mirror (radius $10 \mathrm{~cm}$ ) was placed opposite to the $I_{2}$ detector to reflect back $I_{2}$ fluorescence photons emitted in the same axis but in the opposite direction. Such collection optic assemblies gather photons emitted from the excitation volume and focussed them onto the photocathode of a PCM. Each PCM's photocathode is enhanced for the wavelength range of the fluorescence of interest: $120 \mathrm{~nm}<\lambda<280 \mathrm{~nm}$ (Perkin Elmer MP921RS) and $185 \mathrm{~nm}<\lambda<650 \mathrm{~nm}$ (Perkin Elmer MP943RS). A sampling time of $1 \mathrm{~s}$ is set in both PCMs. Thus, fluorescence and background signals (count rates) are given in counts per second $\left(\mathrm{c} \mathrm{s}^{-1}\right)$.

\subsection{Data acquisition and ancillary measurements}

For continuous instrument data logging the PCMs are interfaced to a PC via an external USB-RS232 multiport interface. 5V DC power for the PCMs and 24V DC for pressure transducers, relays (used to open and close solenoid valves and shutters (see below)) and mass flow controllers (MFC) is supplied from a custom built $3 \mathrm{U} 19^{\prime \prime}$ rack control module (IGI Systems Ltd.). This module also functions to log the cell temperature and temperatures at several other locations in the instrument ( 24 bit ADC; T-type thermocouples), the cell pressure (16 bit ADC) and to control the flows of gas through the calibration MFCs via an RS485 digital network (Brooks Instrument Digital SLA5850). PCM device configuration and control, and principal and auxiliary data logging are performed using custom-made software (IGI Systems Ltd). This software allows programming of calibration and field measurement automation routines including aperture, closure of solenoid valves and light shutters and set points of MFCs.

\subsection{Light source}

Intense continuous wave excitation radiation is generated using an electrodeless discharge lamp (EDL) designed and manufactured at IAPS, Latvia (Gross et al., 2000; Smalins et al., 2005). This type of iodine EDL has been well characterised (Spietz et al., 2001) and used in laboratory resonance absorption studies of iodine kinetics (Gómez Martín et al., 2007). The lamp is a sealed quartz bulb (Fig. 2) containing a trace of molecular iodine diluted in $\sim 3$ Torr of buffer gas (argon), where approximately $21 \mathrm{~W}$ of $80 \mathrm{MHz}$ radiofrequency power are discharged. The electromagnetic field is generated straight from the gate coil of a modified Clapp type oscillator circuit working in serial resonance and in class $\mathrm{E}$ amplifier regime (see e.g. Acar et al., 2006 and references therein). By modulation of the lamp current and frequency adjustment the inductively coupled plasma generated is constrained to remain in the so-called $\mathrm{H}$ regime or magnetic mode (Burm, 2008).

A drawback of this approach is the limited lifetime of the lamps, estimated to be around 1000 working hours. Long duration radiofrequency discharge leads to the release of $\mathrm{Si}$ from the quartz walls, which can react with iodine to form iodosilylidyne (ISi) and higher order silicon compounds like silicon tetraiodide. The presence of atomic and ionic silicon and iodo-silicon compounds is revealed by the appearance of numerous bands in the $200 \mathrm{~nm}-300 \mathrm{~nm}$ region of the spectrum of an old lamp (see below). Once most of the iodine has been removed by this slow process, the lamp stops being effective and must be replaced.

Light exits the lamp body through a thin semi-spherical fused silica window, which is interfaced to the fluorescence cell using a Teflon quick-connect coupling as shown in Fig. 2. The radiation is then collimated using a $50 \mathrm{~cm}$ focal length, $12.7 \mathrm{~mm}$ diameter $\mathrm{CaF}_{2}$ plano-convex lens (Thorlabs) and a row of stacked baffles (aperture diameter of $5 \mathrm{~mm}$ ) mounted on a cylindrical lens holder.

The lamp body has a perpendicular side branch (Gross et al., 2000) with spot contact to the cold side of a Peltier thermoelectric module, whose warm side is cooled by an airforced cooler with 6 heat pipes. With this configuration, the side branch of the lamp can be held at a constant temperature 
within the $233 \mathrm{~K}-293 \mathrm{~K}$ range, using a proportional integraldifferential controller (Omron E5GN) in on-off regime via solid state relay switching of the current through the thermoelectric module. This enables controlling the iodine vapour pressure inside the lamp with appropriate accuracy, thus helping to find source spectrum intensity with minimum selfabsorption by keeping the appropriate density conditions in the discharge zone (Spietz et al., 2001). This is illustrated in the top panel in Fig. 3, where it is shown that the optimal side branch temperature (SBT) for iodine atom RF at 26 Torr air is $\sim 243 \mathrm{~K}$. A further decrease in side-arm temperature only decreases the iodine concentration and the emission intensity of the discharge. Such behaviour is well tracked by the normalised absorption factor (Eq. 1) calculated from the emission spectra of the lamp at different SBT and the literature absorption cross sections. Figure 3 a also shows that pressure and/or buffer gas in the fluorescence cell have an influence on the optimal working temperature.

The bottom panel in Fig. 3 shows that for $I_{2}$ the optimal SBT is significantly higher. Here the non-resonance iodine lines shown in Fig. 1a also contribute to excitation, especially those overlapping with the largest $\mathrm{I}_{2}$ absorption cross sections at 184.445 and $187.641 \mathrm{~nm}$. The intensity of these lines increases with increasing temperature (Fig. 1a, triangles and circles), suggesting that the smaller oscillator strengths of these transitions enable larger iodine vapour pressure in the lamp before self-absorption becomes important. Other contribution to enhanced $\mathrm{I}_{2}$ excitation at increasing SBT is that of the $\mathrm{I}_{2} D \rightarrow X$ emission from the lamp itself, which is clearly observed in the lamp spectra at $293 \mathrm{~K}$.

\subsection{Housing and powering}

The instrument (with the exception of the two pumps) is housed in a wheeled $19^{\prime \prime}$ rack ruggedized polypropylene box $(70 \times 70 \times 90 \mathrm{~cm})$. The rack is mounted inside the box on vibration-dumping rubber fixations. The outer part is covered by an insulating reflective material to prevent radiative heating. A portable air conditioning unit can be fitted via $12 \mathrm{~cm}$ soft bellowed tubing to provide closed loop-cooling of the instrument. A $1.4 \mathrm{~kW}$ UPS unit with $10 \mathrm{~min}$ autonomy is mounted inside the box for surge power protection, power cut prevention and stabilisation of the electricity supply, provided from a 13 A extension cable connected to a portable generator or to the general network.

\subsection{Calibration set-up}

In order to put the $\mathrm{I}_{2}$ fluorescence signal in an absolute scale, a simultaneous measurement of $I_{2}$ concentration using an absorption technique is required. Such technique must be sensitive enough to enable the detection of at least the highest $\mathrm{I}_{2}$ concentrations observed in the MBL, i.e. in a range from several to hundreds pptv. The relatively weak absorption band of $\mathrm{I}_{2}$ in the visible $\left(\sim 2 \times 10^{-18} \mathrm{~cm}^{2} /\right.$ molecule $)$ im-

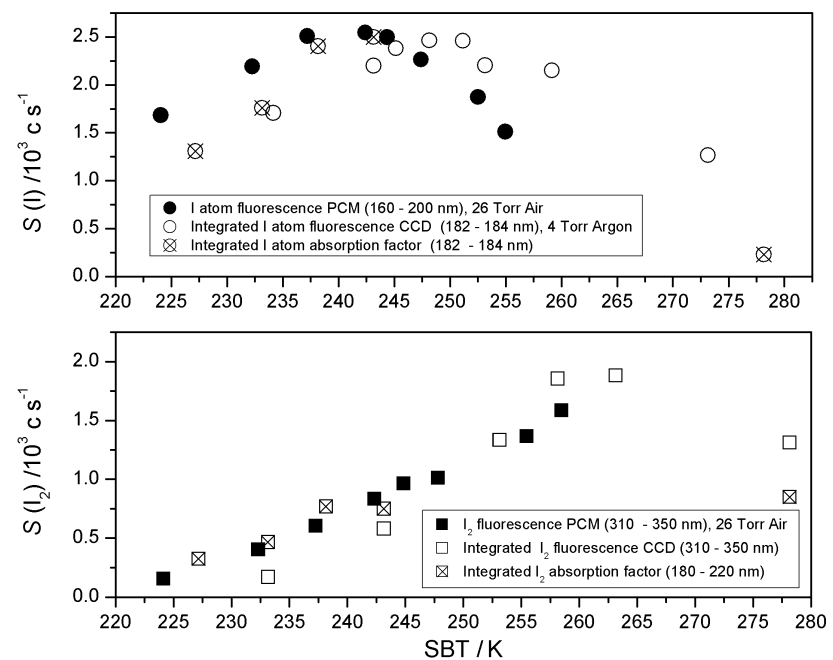

Fig. 3. Fluorescence signal dependence on side branch temperature, SBT (i.e. iodine vapour pressure). Upper panel: I atom fluorescence $S(\mathrm{I})$ registered by photon counting in the range $160-200 \mathrm{~nm}$ (filled circles), integrated dispersed fluorescence of the $183.083 \mathrm{~nm}$ I atom line from a spectrograph-CCD recording (empty circles), and I atom absorption factor (crossed circles). Bottom panel: the same for offresonance $\mathrm{I}_{2}$ fluorescence at the corresponding spectral range. $S(\mathrm{I})$ and $S\left(\mathrm{I}_{2}\right)$ correspond to mixing ratios of 2.5 and $4.8 \mathrm{ppbv}$ in the calibration flow tube. Integrated dispersion fluorescence and absorption factors have been scaled by an arbitrary factor.

plies an extinction of only $5 \times 10^{-9} \mathrm{~cm}^{-1}$ for a mixing ratio $X\left(\mathrm{I}_{2}\right)=100 \mathrm{pptv}$, too small for the classical White or Herriot type multipass cells, but within the reach of a cavityenhanced absorption spectrometer (Fiedler et al., 2003). We have built a portable, robust and cost effective calibration kit based on Incoherent Broad Band Cavity-enhanced Absorption Spectroscopy (IBBCEAS) detection of $\mathrm{I}_{2}$ (Vaughan et al., 2008; Dixneuf et al., 2009; Leigh et al., 2010). Detailed accounts and graphical depictions of this type of instrument are available in the literature, (Vaughan et al., 2008; Washenfelder et al., 2008) so here it is only briefly described. The set-up comprises an enclosed $1.6 \mathrm{~m}$ long optical cavity formed by two high reflectivity mirrors $(R(525 \mathrm{~nm}-$ $555 \mathrm{~nm})>0.99975$, Layertec), a broad band light source (100 W Xe lamp, Lot-Oriel), a Czerny-Turner Spectrograph (SP500i, Acton) equipped with a $1200 \mathrm{gr} / \mathrm{mm}$ grating and a CCD camera (Pixis 400, Acton). The mirrors are mounted on micro-adjustable holders (Los Gatos Research) and protected from $\mathrm{I}_{2}$ deposition by a purging flow of dry air. Mirror calibration is achieved by measuring the Rayleigh scattering extinction in a cavity filled alternatively with air and helium (Washenfelder et al., 2008). Absorption measurements are obtained by alternate measurements of the light leaking out of the cavity in the presence/absence of $\mathrm{I}_{2}\left(\mathrm{I}_{0}(\lambda)\right.$ and $I(\lambda)$, respectively). Reference intensities $I_{0}(\lambda)$ are interpolated for each absorption measurement to correct for lamp drifts. The 
relative intensity change is related to the concentration of $\mathrm{I}_{2}$ by the following expression:

$$
\left(\frac{I_{0}(\lambda)-I(\lambda)}{I(\lambda)}\right)\left(\frac{1-R(\lambda)}{L}+\alpha_{R}(\lambda)\right)=\sigma(\lambda)\left[I_{2}\right]
$$

where $R(\lambda)$ is the mirror reflectivity, $L$ the separation between the mirrors, $\alpha_{R}(\lambda)$ the Rayleigh extinction and $\sigma(\lambda)$ the absorption cross section. The decrease in the effective path length caused by Rayleigh extinction during the measurement of $\mathrm{I}_{0}(\lambda)$ is taken into account by inclusion of the Rayleigh extinction term $\alpha_{R}(\lambda)$ in Eq. (3) as indicated by Washenfelder et al. (2008). In the spectral range considered here and at 720 Torr, Rayleigh extinction amounts to approximately $5 \%$ of the mirror loss. In practice, the separation between mirrors $L$ must be replaced by an effective separation $L_{\text {eff }}$ in order to account for the absorption path length reduction caused by mirror purging. The ratio of back-to-back $\left[\mathrm{I}_{2}\right]$ measurements with and without purging flow gives the path reduction factor, which is typically 0.86 .

Calibration of the fluorescence signal is performed by simultaneous ROFLEX and IBBCEAS sampling from a custom-designed glass flow tube (length $50 \mathrm{~cm}$, diameter $4 \mathrm{~cm}$ ) with optical quality glass windows, carrying a flow of $10 \mathrm{slm}$ synthetic air (Fig. 2). $\mathrm{I}_{2}$ is entrained in the main flow by adding a small flow of synthetic air $(0.1-5 \mathrm{sccm})$ which is passed previously through a $250 \mathrm{~cm}^{3}$ gas washing bottle completely filled with a mixture of glass beads and iodine crystals. In this manner the range of $\mathrm{I}_{2}$ concentrations that can be reached assuming full saturation of the carrier gas is 1-70 ppbv. In practice this is only an upper limit due to equilibration of gas phase $I_{2}$ with walls, and $I_{2}$ concentrations can be as low as a factor of 2 smaller than expected. For lower concentrations the gas washing bottle was closed and $\mathrm{I}_{2}$ degassing from tubing walls was enough to generate measurable mixing ratios down to $50 \mathrm{pptv}$.

Calibration of I atom fluorescence requires a photolysis technique such that the observed loss of $\mathrm{I}_{2}$ can be exclusively attributed to photo-dissociation. It is well known that $\mathrm{I}_{2}$ photolyses in the visible spectral range with a unit quantum yield at high pressure as a result of collisional dissociation of the $B$ state (Rabinowitch and Wood, 1936; Brewer and Tellinghuisen, 1972):

$[\mathrm{I}]=2 \times \Delta\left[\mathrm{I}_{2}\right]=2 \times \phi \times\left[\mathrm{I}_{2}\right]$

where $\phi$ is the photolysis efficiency:

$\phi=\Delta\left[\mathrm{I}_{2}\right] /\left[\mathrm{I}_{2}\right]=\Delta S\left(\mathrm{I}_{2}\right) / S\left(\mathrm{I}_{2}\right)$

Dissociation via $B$ state continuum yields one ground state $\left({ }^{2} P_{3 / 2}\right)$ and one metastable $\left({ }^{2} P_{1 / 2}\right)$ iodine atom (Brewer and Tellinghuisen, 1972; Burde et al., 1974) However, the $\mathrm{O}_{2}$ fraction present in air rapidly quenches any metastable iodine atoms by resonant energy transfer $\left(k=2.6 \times 10^{-11} \mathrm{~cm}^{3} \mathrm{~s}^{-1}\right)$ (Young and Houston, 1983). Note that VUV irradiation as employed by Bale et al. (2008) may not result in a unit photolysis quantum yield (Tellinghuisen and Phillips, 1986; Exton and Balla, 2004).

In the present set-up, a high power Xe lamp (Lot-Oriel, $450 \mathrm{~W}$ or $1000 \mathrm{~W}$, ozone free) was used to photolyse $\mathrm{I}_{2}$ along the sampling tube. This photolysis lamp has a very small output below $260 \mathrm{~nm}$, and therefore potentially interfering concentrations of $\mathrm{O}_{3}$ and/or $\mathrm{OH}$ are not expected (the photodissociation thresholds for $\mathrm{O}_{2}$ and $\mathrm{H}_{2} \mathrm{O}$ are respectively $242 \mathrm{~nm}$ and $246 \mathrm{~nm}$ ). The photolysis efficiency was measured by the relative change of the $\mathrm{I}_{2}$ fluorescence signal and in the absorption signal. Recombination of iodine atoms in the photolysis cell can cause a reduction of the observed photolysis efficiency for large $\mathrm{I}_{2}$ mixing ratios and photolysis rates. However, this does not affect the calibration, since the $[\mathrm{I}]=2 \times \Delta\left[\mathrm{I}_{2}\right]$ equality still holds and the effective $\phi$ is measured for each determination of [I].

\section{Optimisation, calibration and data analysis}

\subsection{Optimisation of detection limit}

The total count rate $S_{\mathrm{T}}$ recorded by a PCMs is given by:

$S_{\mathrm{T}}=S+S_{\mathrm{b}}$

where $S$ is the fluorescence signal and $S_{\mathrm{b}}$ the so-called background signal. The optimisation of the instrument is the process of maximising $S$ without concurrent increase of $S_{\mathrm{b}}$, which is generated by light scattered by the buffer gas (air), by cell walls and by inner components of the instrument (optics).

For a detector recording a small number of discrete events such as a photon counter, the limit of detection is given by (Stevens et al., 1994; Holland et al., 1995):

$\mathrm{LOD}=\frac{S / N}{C(F)} \sqrt{\frac{1}{N_{\mathrm{d}}}+\frac{1}{N_{\mathrm{b}}}} \sigma_{\mathrm{b}}$

where $S / N$ is a given level of signal to noise ratio, $C(F)$ is the sensitivity or fluorescence signal calibration factor in $\mathrm{c} \mathrm{s}^{-1} \mathrm{~cm}^{3}$ atom $^{-1}$ (molecule ${ }^{-1}$ ) (see Eqs. 1 and 2), $N_{\mathrm{d}}$ and $N_{\mathrm{b}}$ the number of accumulations for direct sampling and background sampling respectively and $\sigma_{\mathrm{b}}$ the sample standard deviation of the signal in $\mathrm{c} \mathrm{s}^{-1}$. From counting statistics theory, assuming that the background signals are Poissondistributed, the standard deviation is given by:

$\sigma_{\mathrm{b}}=\sqrt{\frac{S_{\mathrm{b}}}{t}}=\sqrt{\frac{S_{1}+S_{\mathrm{s}}+S_{\mathrm{d}}}{t}}$

where $t$ is the acquisition time of a single data point (1 s), $S_{\mathrm{b}}$ is the total background signal and $S_{1}, S_{\mathrm{s}}$, and $S_{\mathrm{d}}$ are respectively the lamp induced background signal, the solar straylight background signal and the dark signal of the PCM, all in $\mathrm{cs}^{-1}$. In our instrument $S_{\mathrm{s}}+S_{\mathrm{d}}$ is typically negligible 
Table 3. Summary of typical calibration conditions and results.

\begin{tabular}{lrrrrrrrrr}
\hline dataset & $P^{\mathrm{a}}$ & Retro $^{\mathrm{b}}$ & $\varnothing^{\mathrm{c}}$ & $C_{\mathrm{I}_{2}} / 10^{-9 \mathrm{~d}}$ & $S_{\mathrm{b}}\left(\mathrm{I}_{2}\right)^{\mathrm{e}}$ & $\mathrm{LOD}^{\mathrm{f}}$ & $C_{\mathrm{I}} / 10^{-8 \mathrm{~d}}$ & $S_{\mathrm{b}}(\mathrm{I})$ & LOD $^{\mathrm{e}}$ \\
\hline 3 Apr 2010 & 50 & yes & 0.6 & 5.17 & 960 & 20 & 3.24 & 100 & 1.7 \\
23 Apr 2010 & 31 & yes & 0.6 & 1.08 & 600 & 74 & 0.43 & 80 & 6.8 \\
12 May 2010 $^{\mathrm{h}}$ & 31 & yes & 0.6 & 0.56 & 500 & 132 & 0.73 & 80 & 4.0 \\
4 Jun 2010 $^{2}$ & 27 & no & 0.6 & 1.14 & 620 & 71 & 1.62 & 210 & 2.9 \\
8 Jun 2010 & 65 & no/yes & 0.8 & 3.04 & 620 & 27 & 3.79 & 200 & 1.4 \\
5 Oct 2010 & 70 & yes & 0.8 & 10.3 & 1600 & 13 & 5.00 & 365 & 1.2 \\
27 Oct 2010 & 70 & yes & 0.8 & 3.45 & 1300 & 38 & 1.88 & 340 & 3.3 \\
29 Oct 2010k & 70 & no & 0.8 & 3.71 & 1600 & 37 & 2.65 & 360 & 2.4 \\
\hline
\end{tabular}

${ }^{a}$ Pressure in Torr. ${ }^{\mathrm{b}}$ Presence of retro-reflector opposite to $\mathrm{I}_{2} \mathrm{PCM}^{\mathrm{c}}$ Pinhole diameter in mm. ${ }^{\mathrm{d}}$ Sensitivity constant in $\mathrm{c} \mathrm{s}^{-1} \mathrm{molecule}^{-1} \mathrm{~cm}^{3}$. ${ }^{\mathrm{e}}$ Background signal in $\mathrm{c} \mathrm{s}{ }^{-1} .{ }^{\mathrm{f}}$ Limit of detection in pptv for $N_{\mathrm{d}}=N_{\mathrm{b}}=300$ (10 min) and $S / N=1 .{ }^{\mathrm{g}}$ Lamp position changed, leaving the plasma out of focus of the collimating lens. ${ }^{\mathrm{h}}$ Aged lamp, after field campaign. ${ }^{\mathrm{i}}$ New lamp; position of collection and collimation optics optimised, buffer rings with larger diameter. ${ }^{j}$ Same lamp as in the previous row, after 22 days of continuous operation. k New lamp.

( $\left.\sim 1 \mathrm{c} \mathrm{s}^{-1}\right)$ compared to $S_{1}\left(100-365 \mathrm{c} \mathrm{s}^{-1}\right.$ for atomic iodine and $600-1600 \mathrm{c} \mathrm{s}^{-1}$ for $\mathrm{I}_{2}$ ), so that $S_{\mathrm{l}} \approx S_{\mathrm{b}}$.

In order to decrease the detection limit, the ratio $\left(S_{\mathrm{b}}\right)^{1 / 2} / C(F)$ in Eq. (7) must be reduced. This can be done at a fixed concentration of $\mathrm{I}_{2}$ (and I atoms) in the calibration tube, so that the observable quantity to be minimised is just $\left(S_{\mathrm{b}}\right)^{1 / 2} / S$. This is done by increasing the factors contributing to the fluorescence signal $S$ (lamp photon flux $F(\lambda)$, fluorescence yield $Y(\lambda)$, collection efficiency $\Phi$, sampling efficiency $\gamma$, and cell pressure $P_{\text {cell }}$, see Eqs. 1 and 2), without concomitant increase of $S_{\mathrm{b}}$. The particular approach of simultaneous $I$ and $\mathrm{I}_{2}$ detection implies searching for a compromise between optimal detection of both species.

The first step at the instrument design stage is reducing as much as possible the light scattered by the walls (contributing to $S_{\mathrm{b}}$ ), e.g. anti-reflecting coating, collimation of excitation radiation, light beam termination, ring buffers, etc. From the first $\mathrm{I}_{2}$ measurement tests to the first calibration results shown in Table 3, this background-reducing treatment allowed to keep the background signal below $1000 \mathrm{c} \mathrm{s}^{-1}$, implying a factor of $\sim 5$ increase, whereas the sensitivity factor towards $\mathrm{I}_{2}$ was improved by more than 2 orders of magnitude by enhancement of the photon flux $F(\lambda)$ from the lamp and the collection efficiency (included in the efficiency factor $\Phi)$. Further improvement can be observed by comparing the 3 April 2010 and 5 October 2010 calibrations (Table 3).

Notwithstanding these efforts, the major contribution to $S_{\mathrm{b}}$ is still from light scattered by the walls. The contribution to $S_{\mathrm{b}}$ of light scattered by molecules at different buffer gas pressures is shown in Fig. 4. From the top panel it is apparent that a pressure increase between 30 and 100 Torr does not imply a very large increase of $S_{\mathrm{b}}\left(15 \mathrm{cs}^{-1}\right.$ for I and $25 \mathrm{cs}^{-1}$ for $\mathrm{I}_{2}$ ), compared to the background signal registered at 30 Torr (217 $\mathrm{c} \mathrm{s}^{-1}$ and $615 \mathrm{c} \mathrm{s}^{-1}$ respectively).
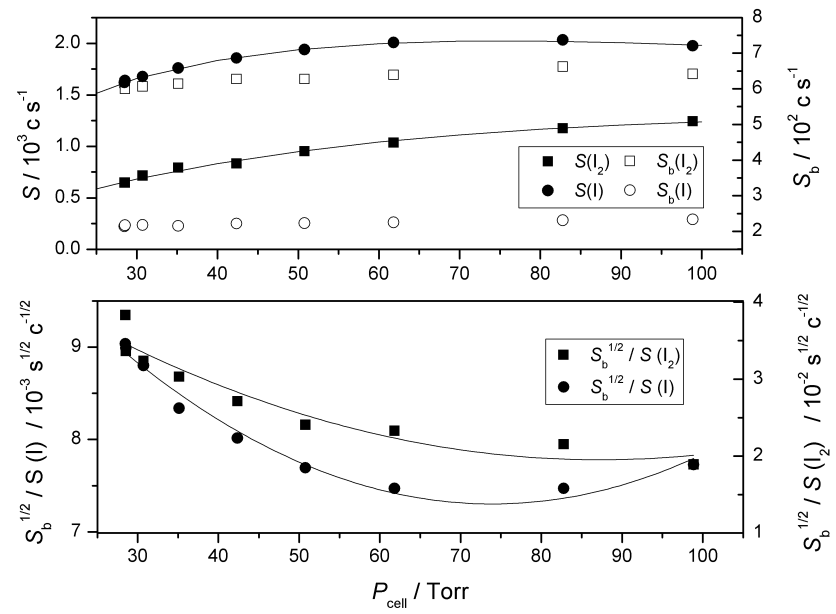

Fig. 4. Pressure dependence of $I$ and $I_{2}$ fluorescence signal $(\mathrm{SBT}=243 \mathrm{~K})$. Top panel: Fluorescence signal (full symbols, left axis) and background (empty symbols, right axis) vs. pressure in the cell. Solid lines are fits of explicit forms of Eqs. (1) and (2) to the experimental data. Bottom panel: ratio of the square root of the background signal to fluorescence signal vs. pressure in the cell. Solid lines are polynomial fits to the data.

In terms of sensitivity enhancement, the optimal value of $P_{\text {cell }}$ for atomic iodine was found to be around 70 75 Torr (Fig. 4). For higher pressures, absorption of both excitation radiation and fluorescence by the $\mathrm{O}_{2}$ SchummanRunge bands, and fluorescence yield decrease by collisional quenching of excited I atom states, counterbalance the larger number density, causing a factor of $\sim 4$ decrease of $S(\mathrm{I})$ between 60 Torr and 180 Torr. On the other hand, the $I_{2}$ fluorescence count rate is an increasing function of $P_{\text {cell }}$, and seems only to level off at higher pressures than considered here as a consequence of reduction of $Y(\lambda)$ by reactive and collisional quenching (Exton and Balla, 2004) counterbalancing 
the increase in total number density $\left(P_{\text {cell }}\right)$. In terms of $\left(S_{\mathrm{b}}\right)^{1 / 2} / S, P_{\text {cell }}=60-75$ Torr can be considered as a good compromise for simultaneous I and $\mathrm{I}_{2}$ detection (Fig. 4, bottom panel).

The selection of a particular pinhole diameter has an impact on the minimum pressure $P_{\text {cell }}$ that can be reached with a rotary pump with fully opened throttle valve, but it seems to have also some influence on the sampling efficiency, which is larger for bigger apertures. Pinholes of $0.4 \mathrm{~mm}, 0.6 \mathrm{~mm}$ and $0.8 \mathrm{~mm}$ where tried. Finally, the pinhole with largest aperture was preferred based on the not very low optimal $P_{\text {cell }}$ mentioned above, and also in the poorer I atom signal observed with the smallest pinhole, which suggested some wall losses (see below).

Collection optics are placed between the fluorescence emitting volume and the photocathodes of the PCMs (Fig. 2). The fluorescence emitting volume is imaged on the photocathodes in order to enhance the collection efficiency factor $\Phi$. Additionally, a concave high reflectivity mirror can be placed opposite to any of the two photocathodes at twice its focal length from the emitting volume. In this way, fluorescence emitted in the opposite direction of the photocathode can be reflected back and the signal enhanced. This approach was tested with $\mathrm{I}_{2}$, resulting in a signal enhancement of 1.37 times, and a noise increase by a factor of 1.77 . This implies an LOD reduction factor of only 0.97 .

The photon flux of the lamp $F(\lambda)$ is another parameter that must be optimised by locating the lamp emitting region on the focus of the collimating lens, setting the optimal current, voltage and frequency in the oscillator circuit and of course by selecting the optimal SBT. As mentioned in Sect. 3.4, there is an optimal SBT for each of the target species, which depends on self-absorption inside the lamp of the different lines of the lamp spectrum which contribute to excitation. Note that an increase in SBT also implies a change in $S_{\mathrm{b}}$, although it does not have the same SBT dependence than $S$, because it does not depend on the overlap of certain atomic lines with the absorption cross sections of gas phase species in the cell. This is illustrated in Fig. 5. The top panel shows the same dataset as in Fig. 3, together with the corresponding background signals. Whilst the total emission from the lamp increases with increasing SBT, as suggested by the linear enhancement of scattered light, the fluorescence signals (specially for I) do not follow the same dependence. The bottom panel shows the quantity $\left(S_{\mathrm{b}}\right)^{1 / 2} / S$ for I and $\mathrm{I}_{2}$. It is clear from this plot that the best compromise for a simultaneous measurement of these species is for $T_{\text {lamp }} \sim 243 \mathrm{~K}$.

Finally, $S\left(\mathrm{I}_{2}\right)$ was found to be proportional to $S_{\mathrm{b}}$ to a good approximation for moderate ( $\sim 10 \mathrm{ppbv})$ to low mixing ratios, which in the absence of other method of lamp monitoring can be helpful for normalisation of $S$ if a lamp drift occurs.
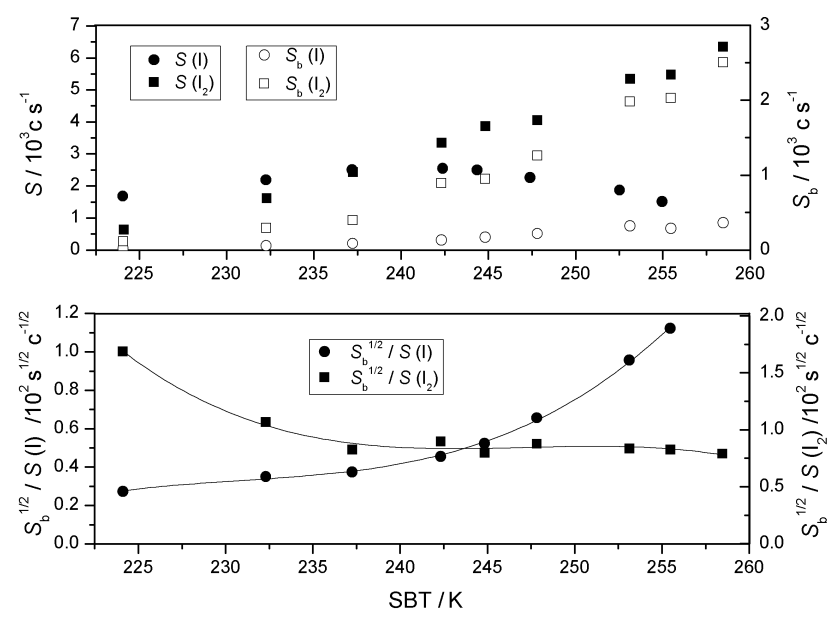

Fig. 5. Background signal dependence on SBT for the same dataset shown if Fig. 3. Top panel: fluorescence signal (filled symbols, left axis) and background signal (empty symbols, right axis) vs. SBT. Bottom panel: ratio of the squared root of the background signal to the fluorescence signal vs. SBT. Solid lines are polynomial fits to the data.

\subsection{Interferences}

In order to study the influence of water vapour on the fluorescence signal, fractions of the carrier gas flow were passed through a bubbler containing de-ionised water, resulting in a range of relative humidities (RH) between $50 \%$ and $100 \%$. At a pressure of 70 Torr in the fluorescence chamber and $100 \% \mathrm{RH}$, the fluorescence signals were lower by a factor of 0.84 and 0.78 for $\mathrm{I}$ atoms and $\mathrm{I}_{2}$ respectively. Therefore, an attenuation factor $\tau$ (RH, $P_{\text {cell }}$ ) (see Eqs. 1 and 2) must be determined for each calibration. In addition, relative humidity changes in the field must be taken into account.

A potential interference from $\mathrm{NO}_{\mathrm{x}}$ and other pollutants was checked by drawing air from the laboratory and from outside the building, and comparing to the signal $S$ observed with only dry synthetic air. Mixing ratios for $\mathrm{NO}$ and $\mathrm{NO}_{2}$ were respectively in the $200-400$ pptv and $1-2$ ppbv ranges. The signal $S$ did not change significantly in the presence of polluted air.

\subsection{Calibration and detection limit}

Typically, a calibration routine implies the following 5 stages, of $200 \mathrm{~s}$ each: $S_{\mathrm{T}}\left(\mathrm{I}_{2}=0\right), S_{\mathrm{T}}\left(\mathrm{I}_{2} \neq 0\right), \mathrm{I}_{2}$ photolysis $\left(S_{\mathrm{T}}(\mathrm{I})\right.$ measurement), again $S_{\mathrm{T}}\left(\mathrm{I}_{2} \neq 0\right)$ and $S_{\mathrm{T}}\left(\mathrm{I}_{2}=0\right)$. These can be prescribed to the ROFLEX software, which controls the set point of MFCs, light shutter, and solenoid valves to provide different concentrations of $\mathrm{I}_{2}$ in the calibration cell, broad band light for I atom generation and background measurements without $I_{2}$. In order to quantify the $I_{2}$ concentration during each ROFLEX operating stage, 100 intensity 


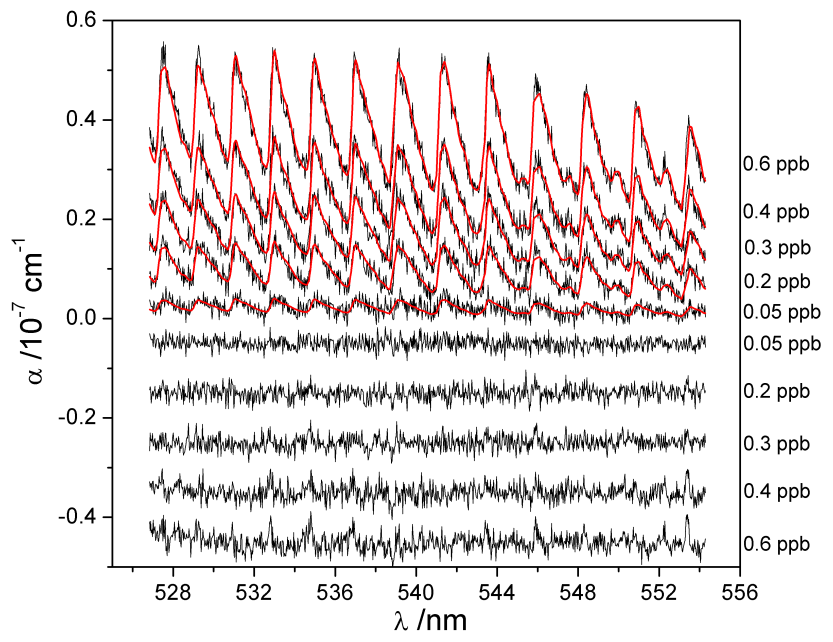

Fig. 6. Series of extinction spectra obtained with the IBBCEAS set up for different $\mathrm{I}_{2}$ mixing ratios. The red lines are the fits to Eq. (3) using a reference spectrum (Saiz-Lopez et al., 2004) convolved to the instrument resolution $(0.22 \mathrm{~nm}$ FWHM). The residuals of the fits are translated vertically for clarity.

measurements through the IBBCEAS optical cavity of $1 \mathrm{~s}$ exposure each are averaged in the CCD detector.

Figure 6 shows a selection of fitted $\mathrm{I}_{2}$ absorption spectra at different concentrations obtained by IBBCEAS. The processed spectra (left hand side of Eq. 3) are linearly fitted by using the $\mathrm{I}_{2}$ reference absorption cross section (Saiz-Lopez et al., 2004) convolved to the spectral resolution of the instrument (typically $0.22 \mathrm{~nm}$ FWHM), to obtain the absolute concentration $\left[\mathrm{I}_{2}\right]$ or mixing ratio $X\left(\mathrm{I}_{2}\right)$ (Vaughan et al., 2008).

The raw data is classified according to the valves and shutter state (Fig. 7). Only the data taken simultaneously to IBBCEAS measurements (100s) is considered in the calculation of an averaged fluorescence signal of the corresponding calibration stage. Similarly to the absorption reference treatment, $S_{\mathrm{b}}$ measurements are interpolated for each measurement of $S_{\mathrm{T}}$ and subtracted out to obtain $S$, as indicated by Eq. (3). The gradient of a linear fit to the plot of $S\left(\mathrm{I}_{2}\right)$ vs. $X\left(\mathrm{I}_{2}\right)$, or $\left[\mathrm{I}_{2}\right]$, (Fig. 8, top panel) is the calibration factor $C_{\mathrm{I}_{2}}(F)$ of Eq. (2).

Photolysis efficiency is calculated for each I atom measurement $\left(\mathrm{I}_{2}\right.$ photolysis phase, see Fig. 7$)$ by interpolating a $S\left(\left[\mathrm{I}_{2}\right]\right)$ to the time when $S\left(\left[\mathrm{I}_{2}\right]-\Delta\left[\mathrm{I}_{2}\right]\right)$ is taken, and then calculating the relative change of the $\mathrm{I}_{2}$ signal (Eq. 5). The I atom concentration is computed using Eq. (4). The gradient of a linear fit to the plot of $S(\mathrm{I})$ vs. $X(\mathrm{I})$ (Fig. 8, bottom panel) is the calibration factor $C_{\mathrm{I}}(F)$ of Eq. (1).

A summary of the calibration factors obtained in the course of this work for different configurations of the instrument is shown in Table 3. The highest sensitivity constants reached were $C_{\mathrm{I}}=(5.0 \pm 1.0) \times 10^{-8} \mathrm{c} \mathrm{s}^{-1}$ atom $^{-1} \mathrm{~cm}^{3}$ and $C_{\mathrm{I}_{2}}=(1.0 \pm 0.2) \times 10^{-8} \mathrm{c} \mathrm{s}^{-1}$ atom $^{-1} \mathrm{~cm}^{3}$. For $S / N=1$, $N_{\mathrm{b}}=N_{\mathrm{d}}=300$ (i.e. $10 \mathrm{~min}$ accumulation time), $S_{\mathrm{b}}(\mathrm{I})=360$

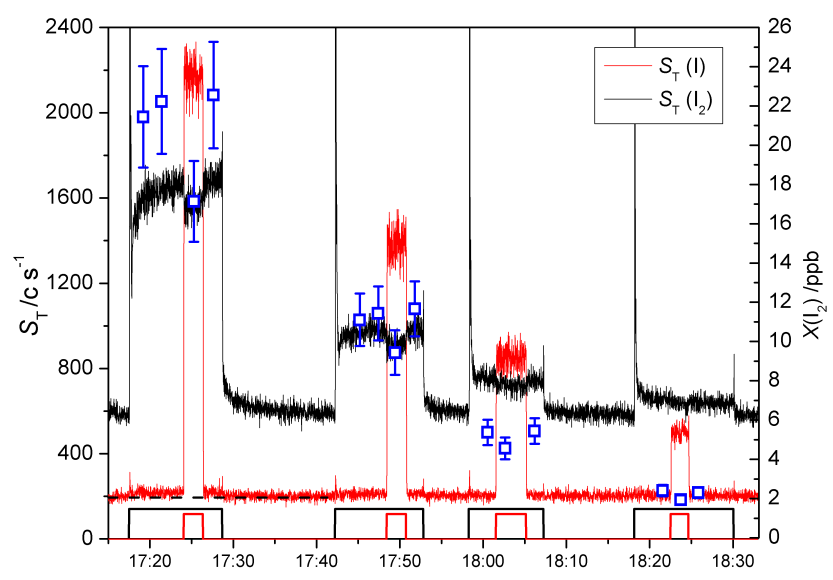

Fig. 7. Calibration raw data. Squared functions indicate direct sampling mode (black) and I 2 photolysis phase (red). The dashed line helps to visualize the small $\mathrm{I}_{2}$ fluorescence signal registered by the I atom PCM. Blue squares: $I_{2}$ mixing ratios retrieved by IBBCEAS. The spikes at the beginning of the direct sampling mode and $\mathrm{I}_{2}$ photolysis phase.
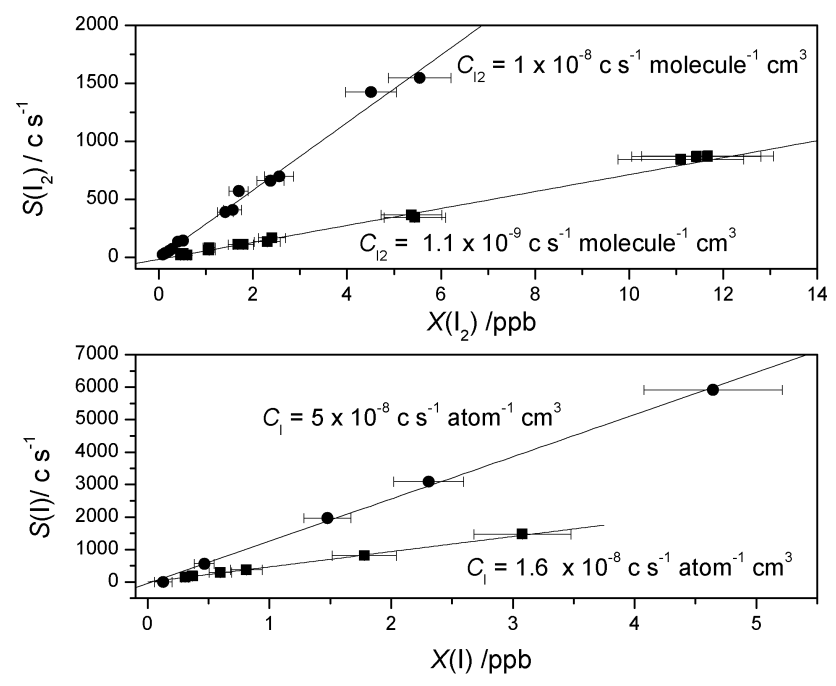

Fig. 8. Examples of calibration fits (4 June 2010 and 5 October 2010, see Table 3). Upper panel: $I_{2}$ fluorescence signal vs. $I_{2}$ mixing ratio in the calibration cell (symbols), and linear fit to the data (solid lines). Lower panel: the same for I atoms.

and $S_{\mathrm{b}}\left(\mathrm{I}_{2}\right)=1600 \mathrm{c} \mathrm{s}^{-1}$, these sensitivity factors result in LODs of $1.2 \mathrm{pptv}$ and $13 \mathrm{pptv}$ respectively. The errors are at $1 \sigma$ level and include the standard error of the mean of the $S_{\mathrm{T}}$ and $S_{\mathrm{b}}$ measurements, the error of the reference absorption cross sections used for retrieving the $\left[\mathrm{I}_{2}\right]$ mixing ratios, the statistical error of the IBBCEAS fit parameters, the uncertainty of the photolysis efficiency determination and the statistical error of the calibration fit (see Table 4). Note that water vapour attenuation will reduce the sensitivity of the instrument in the field by $\sim 20 \%$ at $100 \% \mathrm{RH}$. 
Table 4. Breakdown of the uncertainties associated with $\mathrm{I}_{2}$ concentration and sensitivity factors.

\begin{tabular}{llll}
\hline \multirow{2}{*}{ Quantity } & $\begin{array}{l}\text { Uncertainty } \\
\text { Source }\end{array}$ & Uncertainty $U_{i}, \%$ & $\left(\Sigma U_{i}^{2}\right)^{1 / 2}, \%$ \\
\hline$\left[\mathrm{I}_{2}\right]$ & $R$ & 3 & 16 \\
& $L_{\text {eff }}$ & 8 & \\
& $\sigma\left(\mathrm{I}_{2}\right)$ & 12 & \\
& Spectral fit & 6 & 17 \\
$C_{\mathrm{I}_{2}}$ & {$\left[\mathrm{I}_{2}\right]$} & 16 & \\
& $\mathrm{LS}$ linear fit & 5 & 20 \\
$C_{\mathrm{I}}$ & $C_{\mathrm{I}_{2}}$ & 17 & \\
& $\Delta\left[\mathrm{I}_{2}\right] /\left[\mathrm{I}_{2}\right]$ & 10 & \\
& $\mathrm{LS}$ linear fit & 4 & \\
& &
\end{tabular}

Despite of the use of an interference filter within the collection optics assembly, the I atom PCM still shows some sensitivity to molecular iodine (see Fig. 7). The sensitivity factor is however more than 2 orders of magnitude smaller than the sensitivity through the $\mathrm{I}_{2} \mathrm{PCM}$ and therefore this will not cause any interference in low $\mathrm{I}_{2}$ concentration regime $(<1 \mathrm{ppbv})$.

\subsection{Field deployment}

The instrument was deployed in from 28 April to 8 May 2010 in coastal Galicia, Spain, in the context of a short field campaign in a seaweed rich coastal area, which is the subject of an accompanying paper (Mahajan et al., 2010). During this campaign, the outdoors performance of the instrument was tested and potential problems and weaknesses were identified and corrected. Unfortunately, the optimisation procedure described in Sect. 4.1 had not been completed at the time of the campaign test, and as a consequence $P_{\text {cell }}$ was not set to the optimal value, but to 30 Torr, following the recommendations given by Bale et al. (2008). Eventually this precluded significantly better LODs, as those reached in the laboratory at 60-70 Torr after the campaign, particularly for $\mathrm{I}_{2}$. However, the location of the instrument at a distance of less than $10 \mathrm{~m}$ from the seaweed beds and barely $2 \mathrm{~m}$ aloft the lowest sea level ensured very high, easily detectable concentrations of $\mathrm{I}_{2}$. Indeed, the concentrations observed with the instrument are so far, together with those reported by Huang et al. (2010), the highest observed in the open atmosphere, with peak values of $350 \mathrm{pptv}$ at low tide.

Figure 9 shows an example of the raw data recorded during the campaign. In this particular dataset the time resolution was set to $5 \min \left(N_{\mathrm{b}}=N_{\mathrm{d}}=150, t=1 \mathrm{~s}\right)$. The signature of fluorescence can be distinguished over the noise in the raw signal. The bottom panel hints to one of the major problems found during the campaign, which was the temperature stabilisation inside the instrument housing. The solar radiation and the diurnal temperature cycle largely drove the
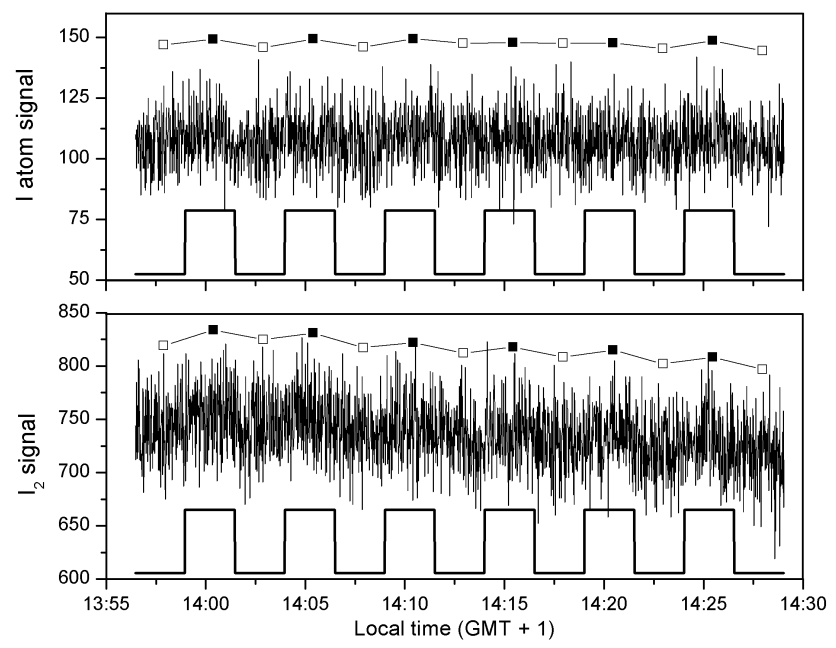

Fig. 9. Example of raw field data. Top panel: I atoms ( $6 \mathrm{pptv})$; bottom panel: $I_{2}(\sim 150 \mathrm{pptv})$. The squared pulse function indicates the 3-way valve state, i.e. the sampling mode (low: background, high: direct). The time basis is $1 \mathrm{~s}$, whereas the time resolution defined by the 3 -way valve state is $300 \mathrm{~s}$ ( $150 \mathrm{~s}$ background $+150 \mathrm{~s}$ direct sampling). Squares represent the averaged signal in the corresponding interval, shifted upwards by an arbitrary constant for clarity. Empty squares refer to background measurements. The size of the squares indicates the standard error of the mean.

temperature changes inside the box, and this had an influence on the $\mathrm{I}_{2}$ cold trap temperature and the SBT before stabilisation measures were undertaken. In Fig. 9, the decreasing $S_{\mathrm{b}}\left(\mathrm{I}_{2}\right)$ corresponds to a cooling period, which implied a reduction of lamp output in the 240-395 nm range. The lamp SBT changes were not important in the case of atomic iodine, since they did not go beyond $\pm 2 \mathrm{~K}$ around $243 \mathrm{~K}$ (see Figs. 3 and 5). For $\mathrm{I}_{2}$, a normalisation of $S\left(\mathrm{I}_{2}\right)$ was done using the changes in $S_{\mathrm{b}}$, based on the proportionality observed in the lab between $S\left(\mathrm{I}_{2}\right)$ and $S_{\mathrm{b}}(240-395 \mathrm{~nm})$. This correction was a maximum of $+10 \%$ of the fluorescence signal $S\left(\mathrm{I}_{2}\right)$.

The other problem related with temperature was the loss of the $I_{2}$ trapping efficiency with increasing temperature: the $I_{2}$ trap has been found to be ineffective above $263 \mathrm{~K}$. To avoid this, the instrument housing was covered in aluminium foil. At some point it was necessary to open the housing lids to avoid the internal build up of heat released by the UPS and other electrical equipment inside the housing box. Generally the data affected by this problem could be saved by interpolation between safe background measurements at low temperature.

The data was scaled to concentration units using sensitivity factors from a calibration previous to the campaign and, in the case of $\mathrm{I}_{2}$, normalised using relative changes of $S_{\mathrm{b}}\left(\mathrm{I}_{2}\right)$ as mentioned above. However, during the last three days of the campaign (Fig. 10) the lamp photon flux started to decrease independently of the SBT. Laboratory measurements after the campaign showed a very drastic decrease of lamp 


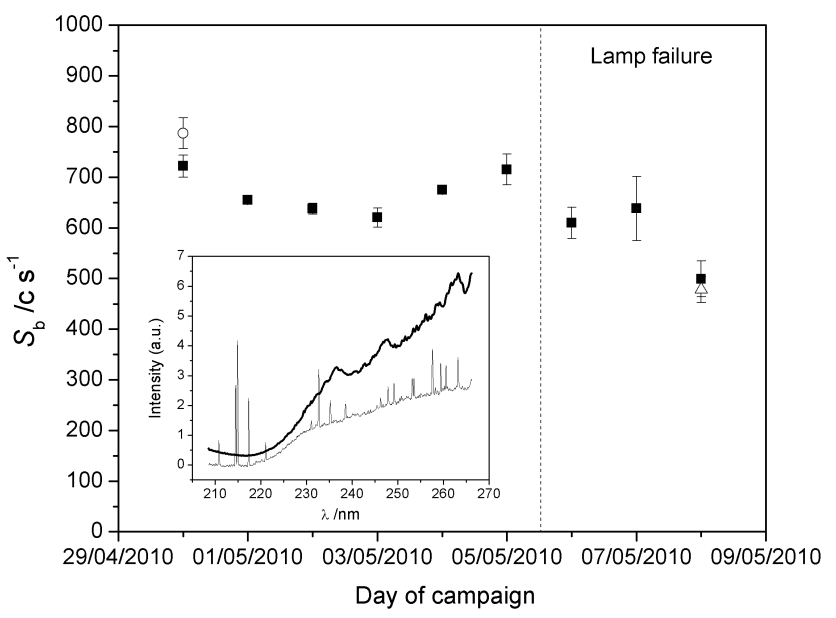

Fig. 10. Evolution of the background signal $S_{\mathrm{b}}\left(\mathrm{I}_{2}\right)$ (black squares) throughout the campaign, compared to the background signals during lab calibrations before (empty circle) and after (triangle) the campaign. The error bars indicate 1 standard deviation of the signal. The insert shows spectra of a fresh (thick line) and an old lamp in the characteristic silicon spectral region.

radiant power and loss of sensitivity by a factor of 4 and 2 for $\mathrm{I}_{2}$ and I respectively. The lack of a response of $S_{\mathrm{b}}$ and $S$ to SBT indicated that the lamp had lost its iodine, as explained in Sect. 3.4. The insert in Fig. 10 shows a spectrum from the old lamp taken after the campaign, together with a spectrum from a fresh lamp. In the latter only the short wavelength flank of the McLennad bands of $I_{2}$ can be observed, whereas the former shows a large number of narrow bands, overlapping with a much weaker McLennand emission. These two observations are hints of the loss of iodine by silicon bonding. Some of the observed lines coincide with $\mathrm{Si}$ and $\mathrm{Si}^{+}$lines (Ralchenko et al., 2008). Some other lines can be attributed to ISi, and some of them, although unassigned, have been previously observed after $\mathrm{SiI}_{4}$ photolysis (Oldershaw and Robinson, 1972).

Notwithstanding these problems, reasonably good datasets where recorded during several days (30 April-5 May) (Mahajan et al., 2010), correlating well with tidal height and ultrafine particle bursts. Figure 11 shows an example of ambient observations for 30 April 2010. Clear atomic and molecular iodine signal appeared with the exposure of sea weed at low tide. The drop of the $\mathrm{I}$ and $\mathrm{I}_{2}$ signal at 13:10 is related to a sudden decrease of SBT during a direct measurement.

As a test, after a rain period and before the algae where exposed again, the pinhole was directly exposed at a distance of about $10 \mathrm{~cm}$ to laminaria samples found at the shoreline, and iodine signal was readily observed, supporting the origin assigned to the low tide signal.
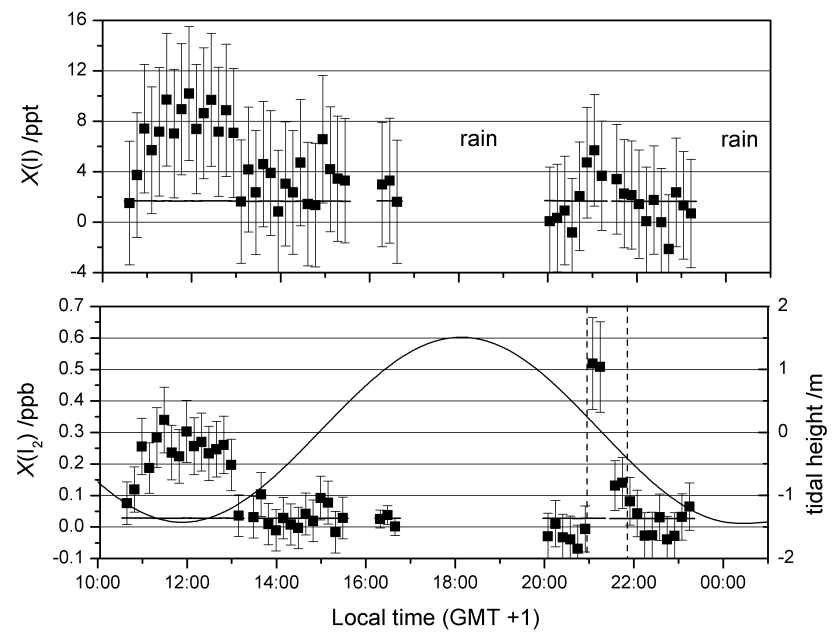

Fig. 11. Example of processed dataset (30 April) for a time resolution of $600 \mathrm{~s}$ ( $300 \mathrm{~s}$ background $+300 \mathrm{~s}$ direct sampling). Thick black lines under the data points indicate the counting statistics LOD for $S / N=1$. The thin solid line in the bottom panel represents tidal height. Vertical dashed lines in the bottom panel bracket a time interval where the pinhole was exposed to seaweed samples at short distance.

\section{Discussion}

\subsection{Comparison to previous work}

Bale et al. (2008) pioneered the measurement of atomic iodine in the atmosphere. Our new instrument presents significant improvements, including: (i) concurrent detection of $\mathrm{I}_{2}$, (ii) straightforward calibration method, (iii) automatic background recording and (iv) use of a more convenient radiofrequency powered EDL system. In terms of performance, our instrument improves the LOD for atomic iodine by a factor of 2 with respect to Bale et al. (2008). Note that in our instrument an interference filter is used to select radiation just from the $178.276 \mathrm{~nm}$ and $183.038 \mathrm{~nm}$ lines of iodine, with a peak transmisivity of only $20 \%$.

Only one boundary layer RF instrument for $\mathrm{BrO}$ has been previously described (Avallone et al., 2003). Most halogen RF instruments have been designed for stratospheric applications and are balloon- or aircraft borne (Anderson et al., 1980; Brune et al., 1989, 1990). Comparison with these instruments is not straightforward, since the oscillator strengths, the excitation power and frequency, the detection schemes employed and the technical realisation are generally very different. In order to make a semi-quantitative comparison, a normalisation to the number density in the fluorescence chamber has to be taken into account (Table 1, column $C_{N}$ ). The sensitivity constant for atomic iodine $C_{N}=$ $\left(P_{\text {env }} / P_{\text {cell }}\right) \times C$ for both (Bale et al., 2008) and our own instrument is not far from that reported for $\mathrm{Br}(\mathrm{BrO})$ boundary layer and air-borne instruments (Avallone et al., 1995, 2003). 
It is noteworthy that the sensitivity of our instrument is still more than one order of magnitude below those reported for chlorine (Anderson et al., 1980; Brune et al., 1985). The reason for this is most likely the aforementioned low population of the $J=3 / 2$ state where the strong transition generating the $178.276 \mathrm{~nm}$ line of iodine originates. In contrast, the energy splitting of the chlorine doublet generating the $118 \mathrm{~nm}$ transitions is extremely small, and therefore the higher energy $J=5 / 2$ state responsible for the strongest transition is significantly populated.

We have demonstrated here the first direct detection of ambient $\mathrm{I}_{2}$ by molecular fluorescence. A similar detection scheme has been employed previously for $\mathrm{Cl}_{2}$ in laboratory studies of the $\mathrm{ClOOCl}$ absorption cross sections (Wilmouth et al., 2009). Note that Bale et al. (2008) derived the $I_{2}$ concentration from the total photolabile iodine content, which is a reasonable approximation only in coastal environments with macroalgae emissions. The ability of measuring $\mathrm{I}_{2}$ concentration, combined with a selective photolysis method, could turn the ROFLEX detection of photolabile iodine content into a molecule-specific quantification method. Compared with online optical detection techniques already tested for $\mathrm{I}_{2}$ in the field (BBCRDS) (Bitter et al., 2005; Leigh et al., 2010) or in the laboratory (IBBCEAS, see Sect. 3.6 and Vaughan et al., 2008), the ROFLEX instrument has a competitive performance with similar integration times. However, mass spectrometric techniques offer a much better performance, with special mention to the APCI/MS/MS technique, with a 2 orders of magnitude better LOD for a similar integration time (Finley and Saltzman, 2008). Further work is needed on the excitation source in order to reduce detection limits by at least an order of magnitude, to reach sensitivities commensurate with the low $\mathrm{I}_{2}$ levels present in remote open ocean locations.

\subsection{Interferences}

\subsubsection{Atomic iodine}

Bale et al. (2008) did not observe a significant change of sensitivity when adding water vapour to the sampled flow in the 0-88\% RH range for $P_{\text {cell }}=20$ Torr. By contrast, we found that for $P_{\text {cell }}=70$ Torr, both the background and the fluorescence signals are significantly affected by the presence of water vapour in laboratory experiments with humidified air (50\%-100\% RH) and by alternative sampling of air from two environments with high RH (coastal, 88\% RH) and low $\mathrm{RH}$ (air-conditioned lab, 33\% RH). Water vapour impacts the fluorescence measurements by absorbing the VUV atomic excitation and fluoresced radiation. The absorption cross section of $\mathrm{H}_{2} \mathrm{O}$ at $183 \mathrm{~nm}$ is $\sim 2.3 \times 10^{-19} \mathrm{~cm}^{2}$ molecule $^{-1}$ (Sander et al., 2006). For a relative humidity of $100 \%$ and $P_{\text {cell }}=70$ Torr, the water vapour concentration in the chamber is $5.3 \times 10^{16}$ molecules $\mathrm{cm}^{-3}$. For a total optical path of the excitation and fluoresced radiation of $14 \mathrm{~cm}$, this corre- sponds to the observed attenuation factor of 0.84 . This is also consistent with the results reported by Bale et al. (2008): for $P_{\text {cell }}=20$ Torr, $88 \%$ RH and a total optical path of $10 \mathrm{~cm}$, the attenuation factor would be 0.97 , which would not change $C_{\mathrm{I}}$ beyond the reported uncertainty. Finally, the consequence of increasing $P_{\text {cell }}$ from 30 to 70 Torr at $100 \% \mathrm{RH}$ is a partial cancellation of the factor of $\sim 2$ increased attenuation factor by water absorption (from 7 to $15 \%$ ) and the $20 \%$ enhancement in $S(\mathrm{I})$ (see Fig. 4).

NO has a complex manifold of Rydberg states originating a highly structured VUV-UV fluorescence spectrum. A potential interference for atomic iodine can be the detection of NO RF and ORF at wavelengths between $180 \mathrm{~nm}$ and $200 \mathrm{~nm}$. In particular, there is an overlap of the $183.0 \mathrm{~nm}$ and $187.6 \mathrm{~nm}$ lines of atomic iodine with the $C\left({ }^{2} \Pi\right)\left(v^{\prime}=1\right) \leftarrow$ $X\left({ }^{2} \Pi\right)\left(v^{\prime \prime}=0\right)$, and $B\left({ }^{2} \Pi\right)\left(v^{\prime}=8\right) \leftarrow X\left({ }^{2} \Pi\right)\left(v^{\prime \prime}=0\right)$ rovibrational bands of NO, respectively, and the $179.9 \mathrm{~nm}$ line of iodine also overlaps with the $D\left({ }^{2} \Sigma^{+}\right)\left(v^{\prime}=1\right) \leftarrow X\left({ }^{2} \Pi\right)$ $\left(v^{\prime \prime}=0\right)$ and the $A\left({ }^{2} \Sigma^{+}\right)\left(v^{\prime}=5\right) \leftarrow X\left({ }^{2} \Pi\right)\left(v^{\prime \prime}=0\right) \mathrm{NO}$ bands (Hikida et al., 1983). The $C\left({ }^{2} \Pi\right)\left(v^{\prime}=1\right)$ state has a very low fluorescence quantum yield of less than $0.1 \%$ resulting from the strong predissociation of ${ }^{2} \Pi$ states over the photodissociation limit (Guest and Lee, 1981). A similarly low fluorescence yield from $B\left({ }^{2} \Pi\right)\left(v^{\prime}=8\right)$ can be expected (Hikida et al., 1983). Energy transfer and electronic quenching of the $C, D$ and $B$ states to the $A$ state by $\mathrm{N}_{2}$ are fast and enhance $A \rightarrow X$ fluorescence from $195 \mathrm{~nm}$ to $350 \mathrm{~nm}$ (Hikida et al., 1983; Imajo et al., 1986; Luque and Crosley, 1999), outside the transmission curve of the $180 \mathrm{~nm}$ interference filter used in our instrument. Indeed, at NO levels typical of a polluted environment, we could not detect fluorescence signal attributable to NO. A number of lab studies have employed the chemical conversion technique to monitor IO by titration with excess $\mathrm{NO}\left(\sim 10^{13}-10^{15}\right.$ molecules $\left.\mathrm{cm}^{3}\right)$ and subsequent detection of atomic iodine by RF (Loewenstein and Anderson, 1985; Canosa-Mas et al., 1999; Bale et al., 2005), and one of them reported the observation of NO fluorescence (Chambers et al., 1992). In principle, it should be possible to use this technique in combination with ROFLEX for in situ detection of IO if the NO fluorescence background is conveniently minimised.

\subsubsection{Molecular iodine}

Water vapour absorbs atomic iodine excitation radiation from the lamp, but not ORF emitted in the $300-350 \mathrm{~nm}$ range. However, the impact of $100 \% \mathrm{RH}$ on $S\left(\mathrm{I}_{2}\right)$ is larger than in $S(\mathrm{I})$, most likely because non-resonance lines from the lamp play a more important role in exciting $I_{2}$ than the resonance lines exciting atomic iodine. The attenuation of $\mathrm{I}_{2}$ signal by water absorption at $100 \%$ RH increases from $10 \%$ at $P_{\text {cell }}=30$ Torr to $22 \% P_{\text {cell }}=70$ Torr, whereas the signal gain is $\sim 100 \%$ (Fig. 4 ). 
There are a number of molecules (dihalogens and interhalogens) with an analogous structure of electronic states, which could absorb photons and emit fluorescence in the same spectral range in which the lamp emits. However, the absorption cross section of the $\mathrm{I}_{2}$ ion-pair $\leftarrow X$ band between $178 \mathrm{~nm}$ and $210 \mathrm{~nm}$ is at least one order of magnitude larger than the ion-pair $\leftarrow X$ cross sections of any other dihalogen or interhalogen (Roxlo and Mandl, 1980; Yencha et al., 1988; Hopkirk et al., 1989; Lawley et al., 1990). Therefore, significant ion-pair $\rightarrow A^{\prime}$ fluorescence of other dihalogens and interhalogens in the 300-400 nm can hardly be expected under atmospheric conditions. For the same reasons, the silicon-related lines (200-300 nm) arising from an aging lamp should not have any further consequence beyond their relationship to iodine loss.

In the field, the instrument responds to exposure to laminaria samples immediately. To date, direct emission of $\mathrm{Cl}_{2}$, $\mathrm{Br}_{2}$ or interhalogens from algae has not been reported, and their presence in the atmosphere is related to halogen recycling in seasalt aerosols. The situation in locations where $\mathrm{I}_{2}$ is present at similar mixing ratios than other dihalogens could be more complicated, but the most likely interfering species would be the interhalogens, and they have been reported at much lower mixing ratios than the dihalogens (Finley and Saltzman, 2008).

NO $A \rightarrow X$ fluorescence extends down to the spectral range where $I_{2}$ fluorescence is collected $(240 \mathrm{~nm}-395 \mathrm{~nm})$ (Hikida et al., 1983; Imajo et al., 1986; Luque and Crosley, 1999). But, again, no interference was observed in a polluted atmosphere. This is consistent with the relatively high LOD of $10 \mathrm{ppb}$ for $1 \mathrm{~min}$ averaging of NO detectors using $A \rightarrow X$ fluorescence (Schwarz and Okabe, 1975). The use of an IO detection scheme by conversion to I by NO would require some modifications to minimise the NO fluorescence background in the $\mathrm{I}_{2}$ signal.

\subsection{Chemical and wall losses}

Potential $\mathrm{I}$ and $\mathrm{I}_{2}$ losses at the inlet walls during calibration could result in the loss of sensitivity and overestimation of the sensitivity factors. The measurement of the photolysis efficiency $\phi$ (Eq. 5) is not affected by $\mathrm{I}_{2}$ wall losses. If $\mathrm{I}$ and $\mathrm{I}_{2}$ wall losses stay constant between calibration and field measurements, the implication would only be a decreased sensitivity for both ( $\gamma<1$ in Eqs. 1 and 2). From modelling of experimental data shown in Fig. 4 (top panel) using Eq. (1), we estimate that up to $17 \%$ of iodine atoms generated in the photolysis cell could be lost in the inlet walls. However, if losses were larger during field measurements (e.g. due to deposition of water and sea salt aerosol), the sensitivity observed in the lab would overestimate that in the field. In order to account for and keep track of possible field-specific wall losses, the instrument is calibrated frequently in the field. We expect that the effects of potential changes in the nature of the inlet surface are accounted for in the variability of the calibration.
If wall-assisted I atom recombination would take place during calibrations, it would not directly affect the calibration validity, but the decrease of the observed photolysis efficiency due to $I_{2}$ regeneration would imply an underestimation of the iodine atom concentration at the pinhole, and therefore an underestimation of $C_{\mathrm{I}}$. Since this is a second order reaction, a noticeable dependence of $\phi$ on $\left[\mathrm{I}_{2}\right]$ (i.e. of [I] Eqs. 4 and 5) could be expected if wall-assisted I atom recombination was fast. However, we observe that $\phi$ is fairly constant up to $10 \mathrm{ppbv}$ of atomic iodine. We estimate that the inlet effective recombination rate coefficient should be as high as $1 \times 10^{-10} \mathrm{~cm}^{3}$ molecule $\mathrm{e}^{-1} \mathrm{~s}^{-1}$ to produce a $30 \%$ decrease of the observed $\phi$ for $X(\mathrm{I})=5$ ppbv. On the other hand $S(\mathrm{I})$ vs. $[\mathrm{I}]=2 \phi\left[\mathrm{I}_{2}\right]$ remains fairly linear in the range of concentrations considered. Therefore, I atom recombination on the inlet walls is likely not to be significant.

Regarding field chemical losses, the residence time of an air parcel in the inlet $(\sim 20 \mathrm{~ms})$ is too short to allow reactions of $\mathrm{I}$ and $\mathrm{I}_{2}$ with ambient trace gases (e.g. with $\mathrm{OH}, \mathrm{O}_{3}, \mathrm{NO}_{\mathrm{x}}$ ), or recycling of $\mathrm{I}$ atoms from the $\mathrm{IO}$ self-reaction or $\mathrm{BrO}+\mathrm{IO}$.

\section{Conclusions}

A new instrument for in situ detection of atomic and molecular fluorescence has been demonstrated in laboratory and field measurements. The instrument extends the scope and capabilities of previous in situ halogen detectors by enabling simultaneous detection of an active halogen species (I) and one of its major precursors $\left(\mathrm{I}_{2}\right)$ at sufficiently low detection limit for a reasonable time resolution (1.2 pptv and $13 \mathrm{pptv}$ respectively for $10 \mathrm{~min}$ integration and $S / N=1$ ), with the potential of providing as well the rest of the atmospheric photolabile content by broad band or selective photolysis, and IO by titration with NO. Such concurrent detection of $\mathrm{I}$ and $\mathrm{I}_{2}$ results also advantageous in the calibration of the instrument, which can be done without resorting to actinometry, thus removing some sources of uncertainty.

Acknowledgements. The authors are grateful to C. S. E. Bale, P. Spietz, M. D. Andrés Hernández, F. Keutsch, E. Boyle, S. Vaughan, J. Orphal and J. M. C. Plane for support and helpful comments. This work was funded by the Spanish Research Council (CSIC) and the Regional Government of Castilla-La Mancha (FGMACLM)

Edited by: D. Toohey

\section{References}

Acar, M., Annema, A.-J., and Nauta, B.: Design Equations for Class-E Power Amplifiers, ProRISC 2006, 17th Annual Workshop on Circuits, Systems and Signal Processing, Veldhoven, The Netherlands, 2006.

Aleksandrov, E. N., Bykhovskii, M. Y., Kozlov, S. N., Katsis, L. F., Kislyuk, M. U., Pyrakhin, G. A., Savkin, V. V., and Fomin, V. 
G.: Sources of radiation of the atomic lines of hydrogen, nitrogen and iodine in the VUV region., Zh. Prikl. Spektrosk., 46, 20-24, 1985.

Allan, B. J., McFiggans, G., Plane, J. M. C., and Coe, H.: Observations of iodine monoxide in the remote marine boundary layer, $\mathrm{J}$. Geophys. Res.-Atmos., 105, 14363-14369, 2000.

Anderson, J. G., Margitan, J. J., and Stedman, D. H.: Atomic Chlorine and the Chlorine Monoxide Radical in the Stratosphere: Three in situ Observations, Science, 198, 501-503, doi:10.1126/science.198.4316.501, 1977.

Anderson, J. G., Grassl, H. J., Shetter, R. E., and Margitan, J. J.: Stratospheric Free Chlorine Measured by Balloon-Borne In Situ Resonance Fluorescence, J. Geophys. Res., 85, 2869-2887, 1980.

Avallone, L. M., Toohey, D. W., Schauffler, S. M., Pollock, W. H., Heidt, L. E., Atlas, E. L., and Chan, K. R.: In situ measurements of BrO During AASE II, Geophys. Res. Lett., 22, 831834, doi:10.1029/95GL00393, 1995.

Avallone, L. M., Toohey, D. W., Fortin, T. J., McKinney, K. A., and Fuentes, J. D.: In situ measurements of bromine oxide at two high-latitude boundary layer sites: Implications of variability, J. Geophys. Res., 108, 4089 doi:10.1029/2002JD002843, 2003.

Baklanov, A. V., Karlsson, L., Lindgren, B., and Sassenberg, U.: Vacuum ultraviolet oscillator strengths of iodine atoms in the $\left({ }^{2} \mathrm{P}_{3 / 2}\right)$ and $\left({ }^{2} \mathrm{P}_{1 / 2}\right)$ states, J. Phys. B: At. Mol. Opt. Phys., 30, L259, doi:10.1088/0953-4075/30/8/001, 1997.

Bale, C. S. E., Canosa-Mas, C. E., Shallcross, D. E., and Wayne, R. P.: A discharge-flow study of the kinetics of the reactions of IO with $\mathrm{CH}_{3} \mathrm{O}_{2}$ and $\mathrm{CF}_{3} \mathrm{O}_{2}$, Phys. Chem. Chem. Phys., 7, 21642172, 2005.

Bale, C., Ingham, T., Commane, R., Heard, D., and Bloss, W.: Novel measurements of atmospheric iodine species by resonance fluorescence, J. Atmos. Chem., 60, 51-70, 2008.

Bitter, M., Ball, S. M., Povey, I. M., and Jones, R. L.: A broadband cavity ringdown spectrometer for in-situ measurements of atmospheric trace gases, Atmos. Chem. Phys., 5, 2547-2560, doi:10.5194/acp-5-2547-2005, 2005.

Braun, W. and Carrington, T.: Line emission sources for concentration measurements and photochemistry, J. Quant. Spectrosc. Ra., 9, 1133-1143, 1969.

Brewer, L. and Tellinghuisen, J. B.: Detection of Iodine Atoms by an Atomic Fluorescence Technique: Application to Study of Diffusion and Wall Recombination, J. Chem. Phys., 54, 5133-5138, 1971.

Brewer, L. and Tellinghuisen, J.: Quantum Yield for Unimolecular Dissociation of $\mathrm{I}_{2}$ in Visible Absorption, J. Chem. Phys., 56, 3929-3938, 1972.

Brewer, P., Das, P., Ondrey, G. S., and Bersohn, R.: Measurement of the relative populations of $\mathrm{I}\left({ }^{2} \mathrm{P}_{1 / 2}^{0}\right)$ and $\mathrm{I}\left({ }^{2} \mathrm{P}_{3 / 2}^{0}\right)$ by laser induced vacuum ultraviolet fluorescence, J. Chem. Phys., 79, 720723, 1983.

Brune, W. H. and Anderson, J. G.: In situ observations of midlatitude stratospheric $\mathrm{ClO}$ and $\mathrm{BrO}$, Geophys. Res. Lett., 13, 13911394, 1986.

Brune, W. H., Weinstock, E. M., Schwab, M. J., Stimfle, R. M., and Anderson, J. G.: Stratospheric ClO: In-situ detection with a new approach, Geophys. Res. Lett., 12, 441-444, 1985.

Brune, W. H., Anderson, J., and Chan, K.: In Situ Observations of BrO Over Antarctica: ER-2 Aircraft Results From $54^{\circ} \mathrm{S}$ to $72^{\circ} \mathrm{S}$
Latitude, J. Geophys. Res., 94(D14), 16639-16647, 1989.

Brune, W. H., Toohey, D. W., Anderson, J. G., and Chan, K. R.: In situ observations of $\mathrm{ClO}$ in the Arctic stratosphere: ER-2 aircraft results from $59^{\circ} \mathrm{N}$ TO $80^{\circ} \mathrm{N}$ latitude, Geophys. Res. Lett., 17, 505-508, 1990.

Burde, D. H., McFarlane, R. A., and Wiesenfeld, J. R.: Quantum efficiencies for the production of electronically excited iodine atoms I (5p5P122) following laser photolysis of I 2 near 5000 Åring, Phys. Rev. A, 10, 1917, doi:10.1103/PhysRevA.10.1917, 1974.

Burm, K.: Breakdown magnetic field in an inductively coupled plasma, Phys. Lett. A, 372, 6280-6283, 2008.

Canosa-Mas, C. E., Flugge, M. L., Shah, D., Vipond, A., and Wayne, R. P.: Kinetics of the Reactions of IO with $\mathrm{HO}_{2}$ and O(3P), J. Atmos. Chem., 34, 153-162, 1999.

Carpenter, L. J., Liss, P. S., and Penkett, S. A.: Marine organohalogens in the atmosphere over the Atlantic and Southern Oceans, J. Geophys. Res., 108, 4256-4269, doi:10.1029/2002JD002769, 2003.

Chambers, R. M., Heard, A. C., and Wayne, R. P.: Inorganic gasphase reactions of the nitrate radical: iodine + nitrate radical and iodine atom + nitrate radical, J. Phys. Chem., 96, 3321-3331, 1992.

Clyne, M. A. A. and Townsend, L. W.: Determination of atomic oscillator strengths using resonance absorption with a Döppler line source: transitions of $\mathrm{Br}$ and $\mathrm{I}(\mathrm{n}+1) \mathrm{s}-\mathrm{np} 5$, J. Chem. Soc., Faraday Trans., 2(70), 1863-1881, 1974.

Davis, D. J., Crawford, J., Liu, S., McKeen, S., Bandy, A., Thornton, D., Rowland, F., and Blake, D.: Potential Impact of Iodine on Tropospheric levels of Ozone and other critical oxidants, J. Geophys Res., 101, 2135-2147, 1996.

Dixneuf, S., Ruth, A. A., Vaughan, S., Varma, R. M., and Orphal, J.: The time dependence of molecular iodine emission from Laminaria digitata, Atmos. Chem. Phys., 9, 823-829, doi:10.5194/acp-9-823-2009, 2009.

Exton, R. J. and Balla, R. J.: ArF laser excitation, collisional transfer, and quench-free fluorescence in I2/foreign gas mixtures, J. Quant. Spectrosc. Ra., 86, 267-283, 2004.

Fiedler, S. E., Hese, A., and Ruth, A. A.: Incoherent broad-band cavity-enhanced absorption spectroscopy, Chem. Phys. Lett., 371, 284-294, 2003.

Finley, B. D. and Saltzman, E. S.: Observations of $\mathrm{Cl} 2, \mathrm{Br} 2$, and I2 in coastal marine air, J. Geophys. Res., 113, D21301, doi:10.1029/2008JD010269, 2008.

Gómez Martín, J. C., Spietz, P., and Burrows, J. P.: Kinetic and Mechanistic Studies of the $\mathrm{I}_{2} / \mathrm{O}_{3}$ Photochemistry, J. Phys. Chem. A, 111, 306-320, 2007.

Gross, U., Ubelis, A., Spietz, P., and Burrows, J.: Iodine and mercury resonance lamps for kinetics experiments and their spectra in the far ultraviolet, J. Phys. D: Appl. Phys., 33, 1588-1591, 2000.

Guest, J. A. and Lee, L. C.: Quantitative absorption and fluorescence studies of NO between 1060 and 2000 A, J. Phys. B: At., Mol. Opt. Phys., 14, 3401-3413, 1981.

Hikida, T., Ishimaru, T., Sannomiya, I., and Mori, Y.: Fluorescence of NO $A{ }^{2} \Sigma^{+}\left(u^{\prime}=5\right), B^{2} \Pi\left(u^{\prime}=8\right)$ and $C^{2} \Pi\left(u^{\prime}=1\right)$ excited by iodine atomic lines, Chem. Phys. Lett., 102, 254-258, 1983.

Holland, F., Hessling, M., and Hofzumahaus, A.: In Situ Measurement of Tropospheric $\mathrm{OH}$ Radicals by Laser- 
Induced Fluorescence: Description of the KFA Instrument, J. Atmos. Sci., 52, 3393-3401, doi:10.1175/15200469(1995)052<3393:ISMOTO>2.0.CO; 2, 1995.

Hopkirk, A., Shaw, D., Donovan, R. J., Lawley, K. P., and Yencha, A. J.: Vacuum-ultraviolet absorption, fluorescence excitation, and dispersed fluorescence spectra of bromine chloride, J. Phys. Chem., 93, 7338-7342, 1989.

Hottle, J. R., Huisman, A. J., Digangi, J. P., Kammrath, A., Galloway, M. M., Coens, K. L., and Keutsch, F. N.: A Laser Induced Fluorescence-Based Instrument for In-Situ Measurements of Atmospheric Formaldehyde, Environ. Sci. Technol., 43, 790-795, 2009.

Huang, R.-J., Seitz, K., Buxmann, J., Pöhler, D., Hornsby, K. E., Carpenter, L. J., Platt, U., and Hoffmann, T.: In situ measurements of molecular iodine in the marine boundary layer: the link to macroalgae and the implications for $\mathrm{O}_{3}$, IO, OIO and $\mathrm{NO}_{\mathrm{x}}$, Atmos. Chem. Phys., 10, 4823-4833, doi:10.5194/acp-10-48232010, 2010.

Imajo, T., Shibuya, K., Obi, K., and Tanaka, I.: Energy transfer and electronic quenching of the low-lying Rydberg states of nitric oxide in nitric oxide/nitrogen mixtures, J. Phys. Chem., 90, 6006-6011, 1986.

Ingle, J. D. and Crouch, S. R.: Spectrochemical Analysis, PrenticeHall, New Jersey, 1988.

Lawley, K. P., Kerr, E. A., Donovan, R. J., Hopkirk, A., Shaw, D., and Yencha, A. J.: Vacuum-ultraviolet absorption and fluoresence excitation spectra of iodine chloride, J. Phys. Chem., 94, 6201-6208, 1990.

Lawrence, G. M.: Resonance Transition Probabilities in Intermediate Coupling for Some Neutral Non-Metals, The Astrophysical Journal, 148, 261-268, 1967.

Leigh, R. J., Ball, S. M., Whitehead, J., Leblanc, C., Shillings, A. J. L., Mahajan, A. S., Oetjen, H., Lee, J. D., Jones, C. E., Dorsey, J. R., Gallagher, M., Jones, R. L., Plane, J. M. C., Potin, P., and McFiggans, G.: Measurements and modelling of molecular iodine emissions, transport and photodestruction in the coastal region around Roscoff, Atmos. Chem. Phys., 10, 11823-11838, doi:10.5194/acp-10-11823-2010, 2010.

Loewenstein, L. M. and Anderson, J. G.: Rate and product measurements for the reactions of hydroxyl with molecular iodine and iodine chloride at $298 \mathrm{~K}$ : separation of gas-phase and surface reaction components, J. Phys. Chem., 89, 5371-5379, 1985.

Luque, J. and Crosley, D. R.: Transition probabilities and electronic transition moments of the $A^{2} \Sigma^{+}-X^{2} \Pi$ and $D^{2} \Sigma^{+}-X^{2} \Pi$ systems of nitric oxide, J. Chem. Phys., 111, 7405-7415, 1999.

Mahajan, A. S., Oetjen, H., Saiz-Lopez, A., Lee, J. D., McFiggans, G. B., and Plane, J. M. C.: Reactive iodine species in a semi-polluted environment, Geophys. Res. Lett., 36, L16803, doi:10.1029/2009GL038018, 2009.

Mahajan, A. S., Sorribas, M., Gómez Martn, J. C., MacDonald, S. M., Gil, M., Plane, J. M. C., and Saiz-Lopez, A.: Concurrent observations of atomic iodine, molecular iodine and ultrafine particles in a coastal environment, Atmos. Chem. Phys. Discuss., 10, 27227-27253, doi:10.5194/acpd-10-27227-2010, 2010.

McFiggans, G., Coe, H., Burgess, R., Allan, J., Cubison, M., Alfarra, M. R., Saunders, R., Saiz-Lopez, A., Plane, J. M. C., Wevill, D., Carpenter, L., Rickard, A. R., and Monks, P. S.: Direct evidence for coastal iodine particles from Laminaria macroalgae - linkage to emissions of molecular iodine, Atmos.
Chem. Phys., 4, 701-713, doi:10.5194/acp-4-701-2004, 2004.

Myer, J. A. and Samson, J. A. R.: Absorption Cross Section and Photoionization Yield of I[sub 2] between 1050 and 2200 [Aring], J. Chem. Phys., 52, 716-718, 1970.

O'Dowd, C. D. and Hoffmann, T.: Coastal new particle formation: a review of the current state-of-the-art, Environ. Chem., 2, 245$255,2005$.

Oldershaw, G. A. and Robinson, K.: Ultraviolet spectra of GeI and SiI: Lower wavelength bands, J. Mol. Spectrosc., 44, 602-604, 1972.

Peters, C., Pechtl, S., Stutz, J., Hebestreit, K., Hönninger, G., Heumann, K. G., Schwarz, A., Winterlik, J., and Platt, U.: Reactive and organic halogen species in three different European coastal environments, Atmos. Chem. Phys., 5, 3357-3375, doi:10.5194/acp-5-3357-2005, 2005.

Rabinowitch, E. and Wood, W. C.: Dissociation of Excited Iodine Molecules, J. Chem. Phys., 4, 358-362, 1936.

Radziemski, J. L. J. and Kaufman, V.: Wavelengths, Energy Levels, and Analysis of Neutral Atomic Chlorine (Cl I), J. Opt. Soc. Am., 59, 424-442, 1969.

Read, K. A., Mahajan, A. S., Carpenter, L. J., Evans, M. J., Faria, B. V. E., Heard, D. E., Hopkins, J. R., Lee, J. D., Moller, S. J., Lewis, A. C., Mendes, L., McQuaid, J. B., Oetjen, H., SaizLopez, A., Pilling, M. J., and Plane, J. M. C.: Extensive halogenmediated ozone destruction over the tropical Atlantic Ocean, Nature, 453, 1232-1235, 2008.

Roxlo, C. and Mandl, A.: Vacuum ultraviolet absorption cross sections for halogen containing molecules, J. Appl. Phys., 51, 29692972, 1980.

Saiz-Lopez, A. and Plane, J. M. C.: Novel iodine chemistry in the marine boundary layer, Geophys. Res. Lett., 31, L04112, doi:10.1029/2003GL019215, 2004.

Saiz-Lopez, A., Saunders, R. W., Joseph, D. M., Ashworth, S. H., and Plane, J. M. C.: Absolute absorption cross-section and photolysis rate of I2, Atmos. Chem. Phys., 4, 1443-1450, doi:10.5194/acp-4-1443-2004, 2004.

Saiz-Lopez, A., Plane, J. M. C., McFiggans, G., Williams, P. I., Ball, S. M., Bitter, M., Jones, R. L., Hongwei, C., and Hoffmann, T.: Modelling molecular iodine emissions in a coastal marine environment: the link to new particle formation, Atmos. Chem. Phys., 6, 883-895, doi:10.5194/acp-6-883-2006, 2006.

Saiz-Lopez, A., Mahajan, A. S., Salmon, R. A., Bauguitte, S. J.-B., Jones, A. E., Roscoe, H. K., and Plane, J. M. C.: Boundary Layer Halogens in Coastal Antarctica, Science, 317, 348-351, 2007.

Sander, S. P., Orkin, V. L., Kurylo, M. J., Golden, D. M., Huie, R. E., Kolb, C. E., Finlayson-Pitts, B. J., Molina, M. J., Friedl, R. R., Ravishankara, A. R., Moortgat, G. K., Keller-Rudek, H., and Wine, P. H.: Chemical kinetics and photochemical data for use in atmospheric studies, JPL-NASA, 2006.

Schwab, J. J. and Anderson, J. G.: Oscillator strengths of $\mathrm{Cl}(\mathrm{I})$ in the vacuum ultraviolet: The 2D-2P transitions, J. Quant. Spectrosc. Ra., 27, 445-457, doi:10.1016/0022-4073(82)900796, 1982.

Schwarz, F. P. and Okabe, H.: Fluorescence Detection of Nitric Oxide in Nitrogen, Anal. Chem. (Washington, DC, U. S.), 47, 703-707, 1975.

Smalins, E., Gross, U., Jansons, J., and Ubelis, A.: Atomic Spectra from RF Electrodeless Discharge Sources for UV and VUV Spectrometry and Analytical Measurements, Meas. Sci. Rev., 5, 
94-97, 2005.

Spietz, P., Gross, U., Smalins, E., Orphal, J., and Burrows, J. P.: Estimation of the emission temperature of an electrodeless discharge lamp and determination of the oscillator strength for the $\mathrm{I}\left({ }^{2} \mathrm{P}_{3 / 2}\right) 183.038 \mathrm{~nm}$ resonance transition, Spectrochim. Acta, Part B, 56, 2465-2478, 2001.

Stevens, P. S., Mather, J. H., and Brune, W. H.: Measurement of tropospheric $\mathrm{OH}$ and $\mathrm{HO} 2$ by laser-induced fluorescence at low pressure, J. Geophys. Res., 99, 3543-3557, 1994.

Tech, J. L.: Analysis of the Spectrum of Neutral Atomic Bromine (BrI), J. Res. NBS - A, 67A, 505-554, 1963.

Tellinghuisen, J.: The McLennan bands of I2: A highly structured continuum, Chem. Phys. Lett., 29, 359-363, 1974.

Tellinghuisen, J. and Phillips, L. F.: Kinetics of iodine following photolysis at $1930 \AA$ : temperature dependence of A'-state quenching, J. Phys. Chem., 90, 5108-5120, 1986.

Vaughan, S., Gherman, T., Ruth, A. A., and Orphal, J.: Incoherent broad-band cavity-enhanced absorption spectroscopy of the marine boundary layer species $\mathrm{I}_{2}$, IO and OIO., Phys. Chem. Chem. Phys., 10, 4471-4477, 2008.
Washenfelder, R. A., Langford, A. O., Fuchs, H., and Brown, S. S.: Measurement of glyoxal using an incoherent broadband cavity enhanced absorption spectrometer, Atmos. Chem. Phys., 8, 7779-7793, doi:10.5194/acp-8-7779-2008, 2008.

Wilmouth, D. M., Hanisco, T. F., Stimpfle, R. M., and Anderson, J. G.: Chlorine-Catalyzed Ozone Destruction: Cl Atom Production from ClOOCl Photolysis, J. Phys. Chem. A, 113, 14099-14108, 2009.

Yencha, A. J., Donovan, R. J., Hopkirk, A., and Shaw, D.: Vacuumultraviolet absorption, fluorescence excitation, and dispersed fluorescence spectra of iodine bromide, J. Phys. Chem., 92, 55235529, 1988.

Yoshino, K., Esmond, J. R., Cheung, A. S.-C., Freeman, D. E., and Parkinson, W. H.: High resolution absorption cross sections in the transmission window region of the Schumann-Runge bands and Herzberg continuum of $\mathrm{O}_{2}$, Planet. Space Sci., 40, 185-192, 1992.

Young, A. T. and Houston, P. L.: The $\left.\mathrm{I}^{2} \mathrm{P}_{1 / 2}\right)+\mathrm{O}_{2}<->$ $\mathrm{I}\left({ }^{2} \mathrm{P}_{3 / 2}\right)+\mathrm{O}_{2}\left({ }^{1} \Delta\right)$ equilibrium, J. Chem. Phys., 78, 2317-2326, 1983. 